\title{
A Predictive Model for Discrete Cell Gravure Roll Coating
}

\author{
N. Raske ${ }^{a}$, R. Hewson ${ }^{a}$, N. Kapur ${ }^{b}$, G. de Boer $^{b}$ \\ a) Department of Aeronautics, Imperial College London, SW7 2AZ, UK \\ b) School of Mechanical Engineering, University of Leeds, Leeds. LS2 9JT, UK \\ n.raske@imperial.ac.uk,r.hewson@imperial.ac.uk,n.kapur@leeds.ac.uk,g.n.deboer@leeds.ac.uk
}

\begin{abstract}
A heterogeneous multiscale model for discrete cell gravure roll coating is presented along with experimental results for the purpose of model validation. The cell volume, generalized cell shape and the gravure patterning are considered in the model which is based on a multiscale description of the flow in the coating bead. The inclusion of a webto-roll contact term accounts for the special gravure case when the web-roll separation tends to zero. The results show how the coating bead responds to changes in operating conditions. These are presented as profile plots of the fluid properties and coating bead shape.
\end{abstract}

Keywords: gravure, multiscale, coating, simulation

\section{Introduction}

Thin film fluid coating and printing describe the process of replacing an initial fluid phase (typically a gas) in contact with the web (also commonly called a substrate) with another fluid phase (typically a liquid) to alter the web's surface properties. Both coating and printing processes are of major industrial interest, being frequently encountered in the production of paper products, polymer sheets and a wide range of printed electronics. It is the latter which has attracted increasing attention in recent years, as printing of electronic circuitry and wide area coating, for example, lighting or photovoltaic applications (Krebs, 2009) places new requirements on coating and printing process technologies [(Michels et al., 2014), (Pudas et al., 2005), (Mäkelä et al., 2007), (Jin et al., 2010), (Jalkanen et al., 2012), (Kumar, 2015)]. 
Many of the fundamental fluid transfer mechanisms are common to both coating and printing processes with the difference being that coating processes deposit a continuous fluid film onto the web (typically as uniformly, thinly and quickly as possible) and printing deposits discrete patterns which in printed electronics may form parts of the printed circuitry (Pudas et al., 2004), potentially comprising multiple fluids, for example transistors (Tobjörk et al., 2008).

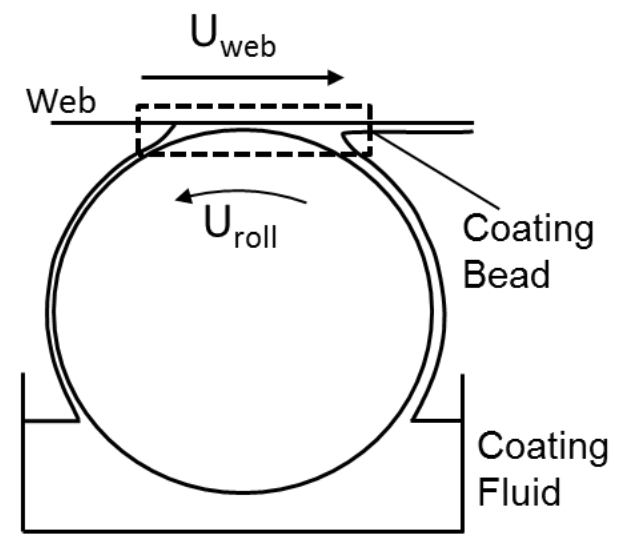

Figure 1: Gravure roll operating in reverse mode. The coating bead is highlighted as the fluid transfer region that forms between the web and the roll.

A diverse range of coating techniques are used in industry, reel-to-reel (R2R) configurations are frequently used to deliver high process efficiency. In such R2R processes the continuous web traverses the coating bead (fluid region between the web and the roll, Figure 1) where the fluid transfer process occurs, some additional processing then typically occurs, such as drying, curing, stretching of the web and/or additional coating processes, before the web is rewound onto another roll. The fluid transfer mechanisms used in R2R coating include slot coating (Romero et al., 2006), curtain coating (Becerra and Carvalho, 2011) and roll coating (Gaskell et al., 1998). A variety of continuous coating processes exist, with gravure roll coating being a frequently encountered subset of the $R 2 R$ set. The gravure roll coating process is one where one of the fluid transfer roll has a topographical pattern on the surface 
(typically etched, knurled or engraved). The gravure roll can operate in either the direct (Kapur, 2003) or the offset mode (Kapur et al., 2001), where the gravure is in direct contact with the passing web, or a second roll is used to transfer the fluid from the gravure roll to the web. The patterned surface topography can comprise of continuous channels (trihelical rolls), periodically spaced cells (discrete cells) or linked cells (Poole, 1981). The gravure roll coating process is typically referred to as a metered coating process as the volume of fluid entering the coating bead is controlled by the volume of the topographical features, with excess fluid removed (also known as doctoring or metering) from the roll surface by means of a doctor blade. The process of doctoring the patterned roll is itself of interest as the volume of fluid entering the bead is of major importance to the coating process (Hanumanthu, 1999). The roll turns in an open-air tray or anilox chamber where the cells are filled. As the excess fluid is removed the fluid is controlled solely by the topographic volume and roll peripheral velocity. The gravure coating process typically results in coated fluid film thicknesses on the order of $10 \mu \mathrm{m}$ which can be deposited at speeds up to $15 \mathrm{~m} / \mathrm{s}$ (Booth, 1970).

Experimentalists have identified the web-to-roll speed ratio, viscosity, surface tension, wrap angle and web tension as the operating parameters that affect film thickness, the most significant of these being the speed ratio. Numerous authors have used numerical techniques to investigate the fluid evacuation of one or a small grid of cells, a process that is a computationally complex for both the case of gravure printing, where focus is on the migration of a discrete volume of fluid [(Huang et al., 2008), (Dodds et al., 2009), (Dodds et al., 2011)], and coating, where focus is on the continuous transfer of fluid [(Schwartz et al., 1998), (Powell et al., 2000), (Hoda and Kumar, 2008)].

Modelling the gravure roll coating process has presented a number of challenges, not least computational resolution required to model the flow in individual cells as well as the fluid transfer bead, this presents a significant increase in complexity when compared to the smooth 
roll coating problem, which has generally been modelled using the lubrication approximation [(Greener and Middleman, 1979), (Benkreira et al., 1982), (Coyle et al., 1990), (Carvalho and Scriven, 1997), (Gaskell et al., 1998)]. The results of such analysis generally compare well with experimental results. Similar approximations (i.e. neglecting inertial effects in the Navier-Stokes equation) have been used to model rolls with trihelical topography (Hewson et al., 2006) (note that the film thicknesses reported in figures 8 and 10 are incorrectly an order of magnitude too small).

In the case of roll coating where the web is unsupported there is a force balance that arises between the hydrostatic fluid pressure (acting normal to the roll surface) and the force derived from the web tension and curvature. This leads to a fluid filled gap which has been analyzed by considering a flexible web where the lubrication equations are coupled to those governing the web curvature [(Rees, 1995), (Gaskell et al., 1998), (Yin and Kumar, 2005), (Yin and Kumar, 2006)]. A particular challenge of the flexible web case is when the gap is reduced to zero and the web and roll are in contact. For a smooth roll under such conditions fluid transport through the coating bead is not possible and therefore all the fluid is transferred to the web or drains down the coating roll. In the gravure case, however, fluid may pass beneath the web in a cell and, therefore, a continuous flux between the upstream and downstream menisci is maintained. The presence of a continuous coating bead separates the reverse gravure coating case from forward gravure printing cases which instead form a discrete liquid bridge between the web and some surface feature on the coating roll [(Dodds et al., 2009), (Dodds et al., 2011)]. Experimental authors have reported scratches on the web indicating contact between the web and roll (Kapur, 1999).

The analysis of thin film type flows with periodic topographical features, as is the case for gravure coating, have been considered by researchers investigating the lubrication of bearings with surface topography. Many of these models are based on a method of flow factors 
derived using homogenization techniques [(Patir and Cheng, 1978), (de Kraker et al., 2007), (de Kraker et al., 2010), (Sahlin et al., 2007)] which are well suited to problems where the governing phenomena operate on two (or more) disperate scales. Also applicable to this separation of scales are the Heterogenous Multiscale Methods (HMM) (E et al., 2003), and these have been applied to similar bearing lubrication problems [(Gao and Hewson, 2012), (de Boer et al., 2014), (Gao et al., 2015), (Gao et al., 2016), (Pérez-Ràfols et al., 2016)]. Recently, (De Boer et al., 2016) derived a model for incorporating the HMM which is directly comparable to flow factor methods. Hewson et al. (2011) was the first to adopt the HMM for the analysis of gravure coating, however their model was restricted to a two dimensional topography. The present study expands this model to investigate three dimensional topography, industrially representative web tensions and web-to-roll contact. The study has been conducted in two parts: (i) Experimental measurements are made of the fluid transfer process for two gravure rolls with known topography; and (ii) a multiscale model is derived to a represent the two rolls in operation, where the dimensions and operating parameters are varied in order to better understand how they effect the coating process. The results section then presents the experimental and computional results together from which disucssions and conclusions are made. 


\section{Experimental Methods}

The experimental procedure presented here is similar to that found in (Kapur, 2003). The primary purpose is to provide data on which the computational model derived in Section 3 is validated.

The laboratory scale coating apparatus shown in Figure 2 has been designed to reproduce the typical coating process encountered in industry. The scaled down test rolls were $10 \mathrm{~cm}$ in diameter by $20 \mathrm{~cm}$ long across which the $23 \mu \mathrm{m}$ thick and $10 \mathrm{~cm}$ wide web was passed. The coating apparatus was setup to operate in reverse mode (i.e. the web and roll pass through the coating bead in opposite directions). The web was subjected to a tension of $1000 \mathrm{~N} / \mathrm{m}$ load and a wrap angle of $2.5^{\circ}$ on the upstream side of the coating bead (upstream and downstream are defined with respect to the web). The roll speed $\left(\mathrm{U}_{\text {roll }}\right)$ was fixed at $0.5 \mathrm{~m} / \mathrm{s}$ while the web speed $\left(\mathrm{U}_{\mathrm{web}}\right)$ was varied to achieve the desired test range of $\mathrm{S}=\left|\mathrm{U}_{\mathrm{web}} / \mathrm{U}_{\text {roll }}\right|=0.5$ to 1.25 .

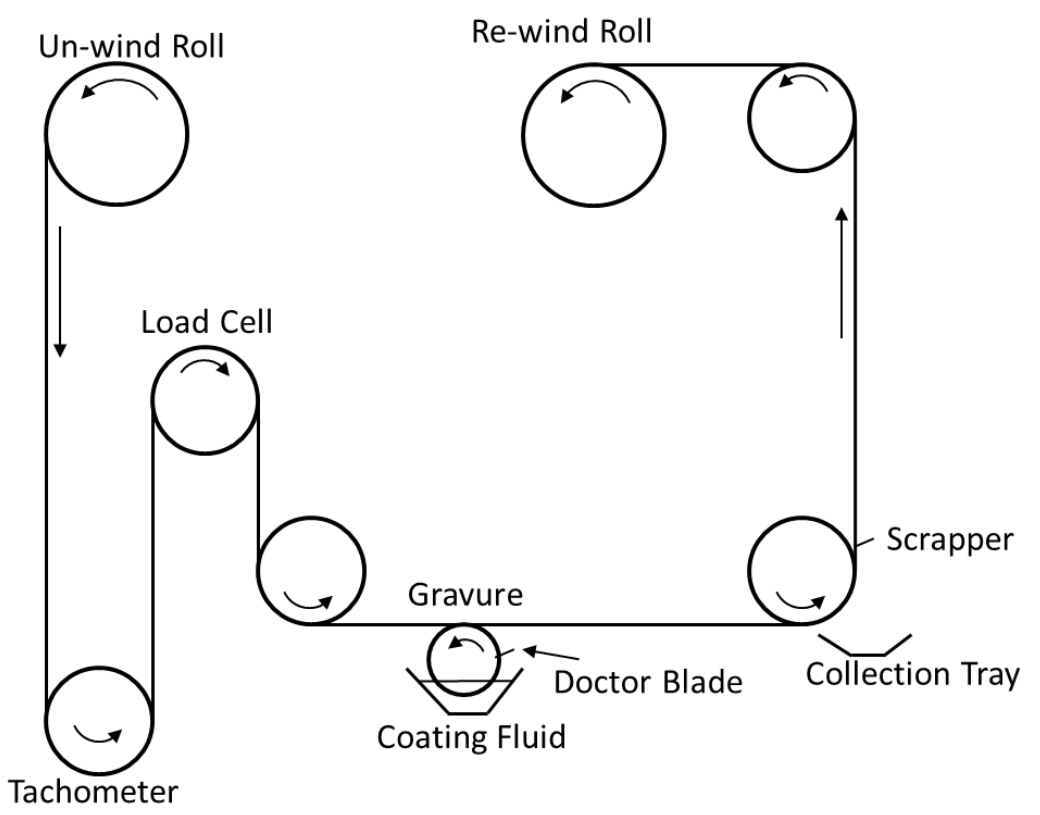

Figure 2: Illustration of coating rig web handling, gravure location and position of fluid removal via the scrapper and gathered in the collection tray for measurement. 
The test fluid was contained in an open-air tray, the composition of which was $20 \%$ (by weight) glycerol, $79 \%$ water mixture with a $1 \%$ surfactant, Tween20 (polyoxyethylenesorbitan monolaurate) to ensure the web was completely wetted. The viscosity and surface tension of the resulting test solution were measured to be $0.00163 \mathrm{~Pa}$.s and $0.04 \mathrm{~N} / \mathrm{m}$ respectively.

The test consisted of scraping the fluid off the coated web into a beaker for mass measurement over a time period of 120 seconds. Determination of the cell size on each roll was found using a white light interferometer with a resolution of $3 \mathrm{~nm}$. The characteristics for each roll is shown in Table 1.

Table 1: Test roll characteristics.

\begin{tabular}{|c|c|c|}
\hline Average Cell Values & Roll A & Roll B \\
\hline Characteristic Length (L) & $0.250 \mathrm{~mm}$ & $0.450 \mathrm{~mm}$ \\
\hline Cell Diameter (2R 0 ) & $0.150 \mathrm{~mm}$ & $0.300 \mathrm{~mm}$ \\
\hline Max Cell Depth (D) & $0.080 \mathrm{~mm}$ & $0.175 \mathrm{~mm}$ \\
\hline Cell Volume & $8.9 \times 10^{-13} \mathrm{~m}^{3}$ & $7.5 \times 10^{-12} \mathrm{~m}^{3}$ \\
\hline Volume per Unit Area & $1.4 \times 10^{-5} \mathrm{~m}^{3} / \mathrm{m}^{2}$ & $3.7 \times 10^{-5} \mathrm{~m}^{3} / \mathrm{m}^{2}$ \\
\hline
\end{tabular}

\section{Computational Methods}

The method here builds on the multiscale approach for analyzing gravure rolls by Hewson et al. (2011), extending it beyond the two-dimensional test case to real roll geometries and 
operating configurations. It exploits the periodicity of the gravure topography, allowing a homogeneous representation of the governing fluid flow equations to be derived for the flow in the coating bead. The method captures the effect of the complex three-dimensional flow inside a gravure cell. The length scale of the coating bead is at least one order of magnitude larger than that of the cell (however, on a typical roll this separation of scales can be two or more orders of magnitude). This paper refers to the large scale and the small scale with the former being the coating bead length scale (Figure 3) and the latter being the cell length scale (Figure 4).

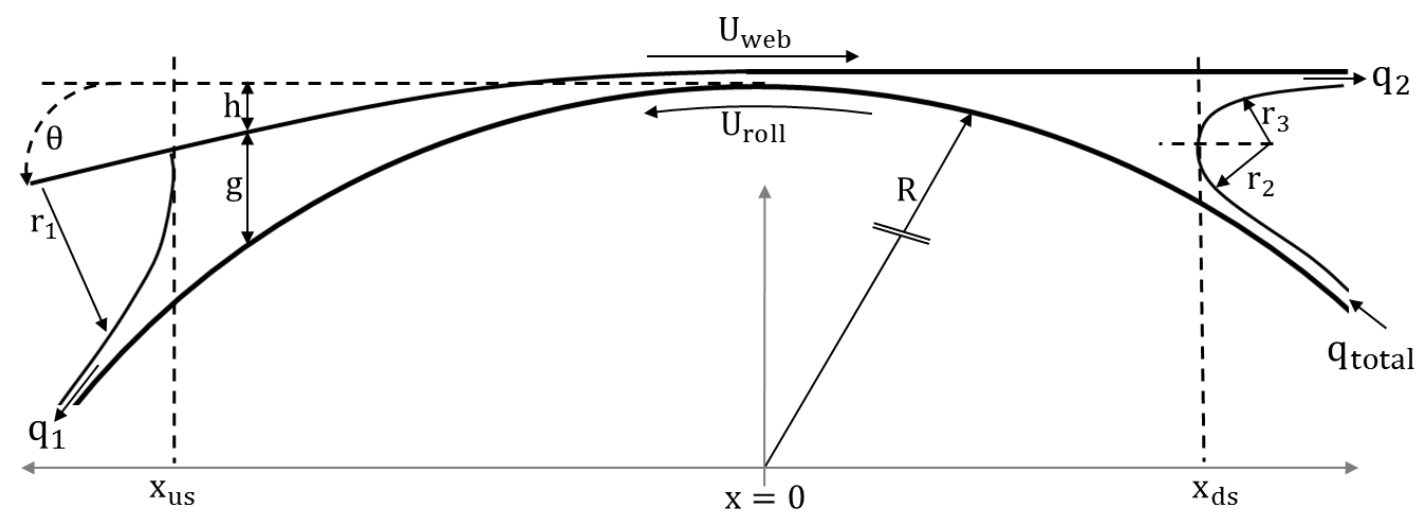

Figure 3: Cross section of the coating bead highlighted in Figure 1. This forms the large scale domain and neglects the explicit definition of the gravure cells.

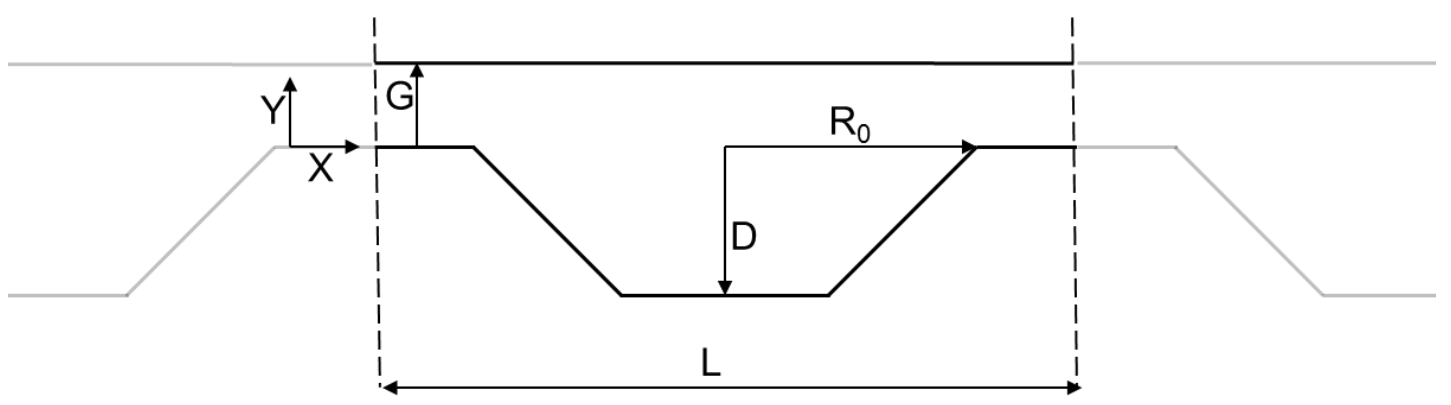

Figure 4: Cross section of an idealized gravure cell forming the small scale domain. The length $L$ is the characteristic length used to make the physical parameters non-dimensional. 


\begin{tabular}{|c|c|}
\hline$\frac{\mathrm{U}_{\mathrm{web}}}{\mathrm{U}_{\text {roll }}}=\mathrm{S}$ & 1 \\
\hline$\frac{\left(R, R_{0}, D, G, H, X, Y, Z\right)}{L}=r, r_{0}, g, h, x, y, z$ & 2 \\
\hline$\frac{\mathrm{PL}}{\eta U_{\text {roll }}}=p$ & 3 \\
\hline$\frac{\mathrm{T}}{\eta \mathrm{U}_{\text {roll }}}=\mathrm{t}$ & 4 \\
\hline$\frac{\mathrm{Q}}{\mathrm{LU}_{\text {roll }}}=\mathrm{q}$ & 5 \\
\hline$\frac{\eta \mathrm{U}_{\text {roll }}}{\gamma}=\mathrm{Ca}$ & 6 \\
\hline
\end{tabular}

The non-dimensional parameters in equation 1 to 6 have been adopted for the computational formulation.

The dimensional quantities are denoted by the capital letters and their dimensionless counterparts are denoted by lower case. $\mathrm{S}$ is the web-to-roll speed ratio, $\mathrm{X}$ and $\mathrm{Y}$ are axis coordinates in the tangential and radial roll directions respectively, $\mathrm{L}$ is the characteristic length of the cell (Figure 4). The fluid properties have also been made non-dimensional where $\mathrm{P}$ is pressure, $\mathrm{T}$ is the web tension, $\mathrm{Q}$ is a volumetric flow rate and $\eta$ is the fluid viscosity. The non-dimensional capillary number $(\mathrm{Ca})$ is used to relate the fluid viscosity and surface tension $(\gamma)$. 


\subsection{Governing Equations}

$$
\mathrm{q}_{\mathrm{x}}=\mathrm{a} \frac{\mathrm{dp}}{\mathrm{dx}}+\mathrm{bS}+\mathrm{c}
$$

From a consideration of the cell length scale the coating bead is assumed to behave as a Stokes fluid. The fluid transfer process is given by a summation of the shear components (from the relative motion of the web and roll) and the pressure driven components (due to the shape of the roll). These components describe the volumetric flow rate through the coating bead via equation 7 . The linearity of Stokes flow is exploited at the small scale only. It was shown in Hewson et al. (2009) that at the cell length scale deformation of the web is negligible, for this reason it is only considered at the large, non-linear scale. This is the case for the treatment of the free surfaces which are assumed to occur at only the upstream and downstream locations as is consistent with experimental observations.

The large and small scales are coupled by the constants a, b and c which are functions of the gap and homogenized small scale data and were calculated numerically. The Heterogeneous Multiscale Method (HMM) used in this paper is described by first presenting the large scale (coating bead) formulation in terms of the coupling constants. These constants are calculated in the small scale, which follows the large scale description.

\subsection{Large Scale}

$$
g=h+\frac{x^{2}}{2 R}
$$


The large scale (Figure 3) was described as a one-dimensional boundary value problem where the menisci define the limits. The large scale gravure surface (smooth equivalent) is approximated as a parabola based on the roll radius. The web-to-roll gap is then related to the gravure surface via Equation 8 where $h$ is the vertical distance from the web to the roll surface and $\mathrm{h}=0$ was chosen arbitrarily to be at the top dead center of the roll.

$$
\Delta \mathrm{p}=-\kappa \mathrm{t}
$$

The web is assumed to be an inextensible membrane under tension, t. Any deformation of the web arises as a reaction to the pressure terms in the coating bead. Equation 9 relates the difference in pressure either side of the web to its curvature, $\kappa$, (Storey, 1996).

$$
\kappa=\frac{\frac{d^{2} y}{d x^{2}}}{\left(1+\left(\frac{d y}{d x}\right)^{2}\right)^{\frac{3}{2}}}
$$

In the Cartesian coordinate frame shown in Figure 3, the curvature of a one-dimensional curve is described by Equation 10 .

\begin{tabular}{|c|c|}
\hline$\frac{\mathrm{dp}}{\mathrm{dx}}=\frac{\mathrm{q}_{\mathrm{x}}-\mathrm{Sb}(\mathrm{g})-\mathrm{c}(\mathrm{g})}{\mathrm{a}(\mathrm{g})}$ & $\mathbf{1 1}$ \\
\hline$\frac{\mathrm{dq}}{\mathrm{dx}}=0$ & 12 \\
\hline
\end{tabular}




$$
\frac{d^{2} h}{d x^{2}}=\frac{p_{f}+p_{c}}{t}\left(1+\left(\frac{d h}{d x}\right)^{2}\right)^{\frac{3}{2}}
$$

The fluid in the coating bead can now be described by the three differential equations 11,12 and 13. Equation 11 is a re-arrangement of equation 7 and is used to solve the pressure gradient along the coating bead. Equation 12 defines the conservation of volume, and in practice indicates that the coating operation is occurring at a steady state. Equation 13 defines the curvature of the web relative to the roll as a function of the pressure forces in the bead.

$$
\mathrm{p}_{\mathrm{c}}=\alpha 10^{\frac{-\mathrm{g}}{\beta}}
$$

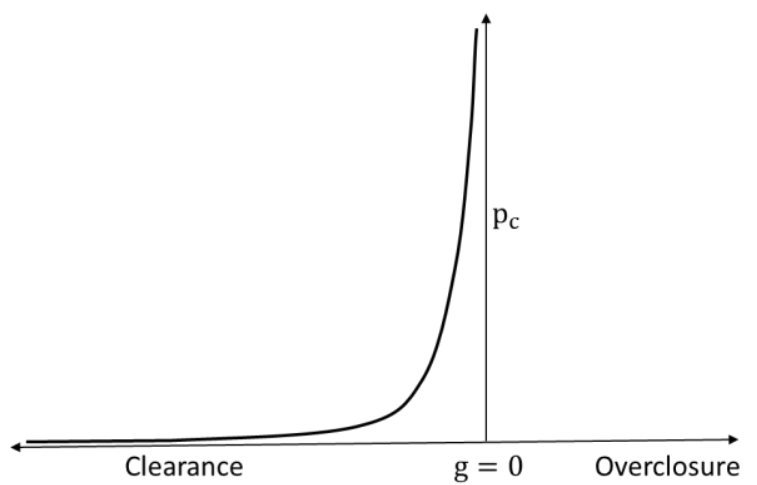

Figure 5: The function $\mathbf{p}_{\mathrm{c}}$ grows exponentially as the gap approaches zero. This prevents numeric overclosure effects.

The normal force acting on the web is equal to the summation of the hydrostatic pressure in the fluid $\left(\mathrm{p}_{\mathrm{f}}\right)$ and the contact pressure $\left(\mathrm{p}_{\mathrm{c}}\right)$ which arises from the solid interaction between the web and roll. The contact pressure can physically be described as a reaction force acting on 
the web. It is numerically described by the function in Equation 14, where $\mathrm{p}_{\mathrm{c}}$ is zero when there is clearance between the web and roll (i.e. the gap is greater than zero) and exponentially rises as the clearance approaches the asymptote at $g=0$, Figure 5 . This enforces the web-to-roll interface and prevents numerical overclosure effects (i.e. the overlapping of numerically defined boundaries) where the gap becomes negative. The constant, $\alpha$, scales the magnitude of $\mathrm{p}_{\mathrm{c}}$ and can be approximated as equal to the web tension value, $\beta$ determines the growth rate of $p_{c}$ and should be small $\left(=10^{-5}\right)$ to minimise the numeric error introduced at gaps near zero.

\begin{tabular}{|c|c|}
\hline$\frac{\mathrm{d} \Psi}{\mathrm{d} \zeta}=0$ & 15 \\
\hline$\frac{\mathrm{dx}}{\mathrm{d} \zeta}=\Psi$ & 16 \\
\hline$\frac{\mathrm{dp}}{\mathrm{d} \zeta}=\Psi \frac{\mathrm{dp}}{\mathrm{dx}}$ & 17 \\
\hline$\frac{\mathrm{dq}}{\mathrm{d} \zeta}=\Psi \frac{\mathrm{dq}}{\mathrm{dx}}$ & 18 \\
\hline$\frac{\mathrm{dh}}{\mathrm{d} \zeta}=\Psi \frac{\mathrm{dh}}{\mathrm{dx}}$ & 19 \\
\hline$\frac{\mathrm{d}\left(\Psi^{-1} \frac{\mathrm{dh}}{\mathrm{d} \zeta}\right)}{\mathrm{d} \zeta}=\Psi \frac{\mathrm{p}_{\mathrm{f}}+\mathrm{p}_{\mathrm{c}}}{\mathrm{t}}\left(1+\left(\Psi^{-1} \frac{\mathrm{dh}}{\mathrm{d} \zeta}\right)^{2}\right)^{\frac{3}{2}}$ & 20 \\
\hline
\end{tabular}

The location of the bounding menisci is not known a priori, therefore requiring an iterative approach. The coating bead was discretized into a 5000 node mesh. A moving mesh technique was adopted where the nodal spacing was adjusted between iterations to account 
for changes in the total length of the coating bead. This was implemented by re-writing the $\mathrm{x}$ axis in terms of an auxiliary variable, $\zeta$, and simultaneously solving for the length of the coating bead as defined by the meniscus derived boundary conditions, described later, and the governing equations. These have been re-written in terms of the auxiliary axis defined by equations 15 and 16. The system of equations was solved using MATLAB's bvp4c first order solver. This results in the coating bead being numerically described by a system of six equations (15-20).

\begin{tabular}{|l|l|}
\hline$\frac{\mathrm{dh}}{\mathrm{dx}}=-\theta$ at $\mathrm{x}=\mathrm{x}_{\mathrm{us}}$ & $\mathbf{2 1}$ \\
\hline$\frac{\mathrm{dh}}{\mathrm{dx}}=0$ at $\mathrm{x}=\mathrm{x}_{\mathrm{ds}}$ & $\mathbf{2 2}$ \\
\hline & \\
\hline
\end{tabular}

To close the problem six boundary conditions are required. Each boundary condition is implemented at the upstream (us) and downstream (ds) menisci. Equations 21 and 22 are used to define the wrap angle, $\beta$, of the web entering and leaving the coating bead.

$$
r=\frac{t}{1.34 \mathrm{Ca}^{\frac{2}{3}}}
$$

$$
x=-\sqrt{2 R\left(\frac{\mathrm{q}_{1}}{1.34(\mathrm{Ca})^{\frac{2}{3}}}-\mathrm{h}\right)} \text { at } \mathrm{x}=\mathrm{x}_{\mathrm{us}}
$$




$$
x=\sqrt{2 R\left(\frac{2 q_{2}}{1.34(\mathrm{SCa})^{\frac{2}{3}} \mathrm{~s}}-\mathrm{h}\right)} \text { at } \mathrm{x}=\mathrm{x}_{\mathrm{ds}}
$$

The length of the coating bead is defined by the distance between the upstream and downstream menisci. In order to determine the menisci locations, the equation developed by Bretherton (1961) is used to relate the radius of meniscus curvature to an asymptotic film thickness (Equation 23). This requires the simplifying assumptions that; 1) the bounding menisci have a constant radius of curvature which is related to the web-to-roll gap and 2) that the asymptotic film thickness can be reasonably approximated by $\mathrm{q}_{1}$ and $\mathrm{q}_{2} / \mathrm{S}$. There is an additional simplification at the downstream where it is assumed that $r_{2}=r_{3}$ (Figure 3). By substituting the meniscus radius for the gap in equation 8 the location on $\mathrm{x}$ axis is given by equations 24 and 25 .

\begin{tabular}{|c|l|}
\hline $\mathrm{p}=\frac{1}{\mathrm{Ca}} \frac{1}{\mathrm{~g}}$ at $\mathrm{x}=\mathrm{x}_{\mathrm{us}}$ & $\mathbf{2 6}$ \\
\hline $\mathrm{p}=\frac{1}{\mathrm{Ca}} \frac{2}{\mathrm{~g}}$ at $\mathrm{x}=\mathrm{x}_{\mathrm{ds}}$ & $\mathbf{2 7}$ \\
\hline & \\
\hline
\end{tabular}

The final two boundary conditions are the non-dimensional form of the Young-Laplace equation (Landau, 1942) which specify the pressure at the menisci (Equations 26 and 27). The assumption is made that the meniscus radius of curvature is related to the gap, $\mathrm{g}$ (Hewson et al., 2011). 


\subsection{Small Scale}

The small scale is defined by the characteristic cell length, given here as the distance from the center of one cell to the next. The fluid on this scale is governed by Stokes flow and therefore can be described as a linear function of $\mathrm{S}$ and $\mathrm{dp} / \mathrm{dx}$. It is coupled to the large scale via Equation 7. The coefficients $\mathrm{a}, \mathrm{b}$ and $\mathrm{c}$ are solved simultaneously by calculating for the volumetric flow rate through the cell domain at the conditions specified in Table 2. Conditions 1 and 2 simulate a pressure driven flow and a shear driven flow respectively, and require a change in reference frame to one in which the roll is stationary relative to the web. The third condition is tractable analytically as there is no relative motion between the web and roll. The coefficients are implemented in the large scale via a lookup table as a function of the gap.

Table 2: The three boundary conditions used to determine the small scale coupling coefficients.

\begin{tabular}{|c|c|c|}
\hline Condition 1 & Condition 2 & Condition 3 \\
\hline $\mathrm{u}_{\mathrm{web}}^{*}=0$ & $\mathrm{u}_{\mathrm{web}}^{*}=1$ & $\mathrm{u}_{\mathrm{web}}^{*}=-1$ \\
\hline g $\quad \Delta \mathrm{p}^{*}=-1$ & $\Delta \mathrm{p}^{*}=0$ & $\Delta \mathrm{p}^{*}=0$ \\
\hline $\mathrm{u}_{\mathrm{roll}}^{*}=0$ & $\mathrm{u}_{\mathrm{roll}}^{*}=0$ & $\mathrm{u}_{\text {roll }}^{*}=-1$ \\
\hline
\end{tabular}




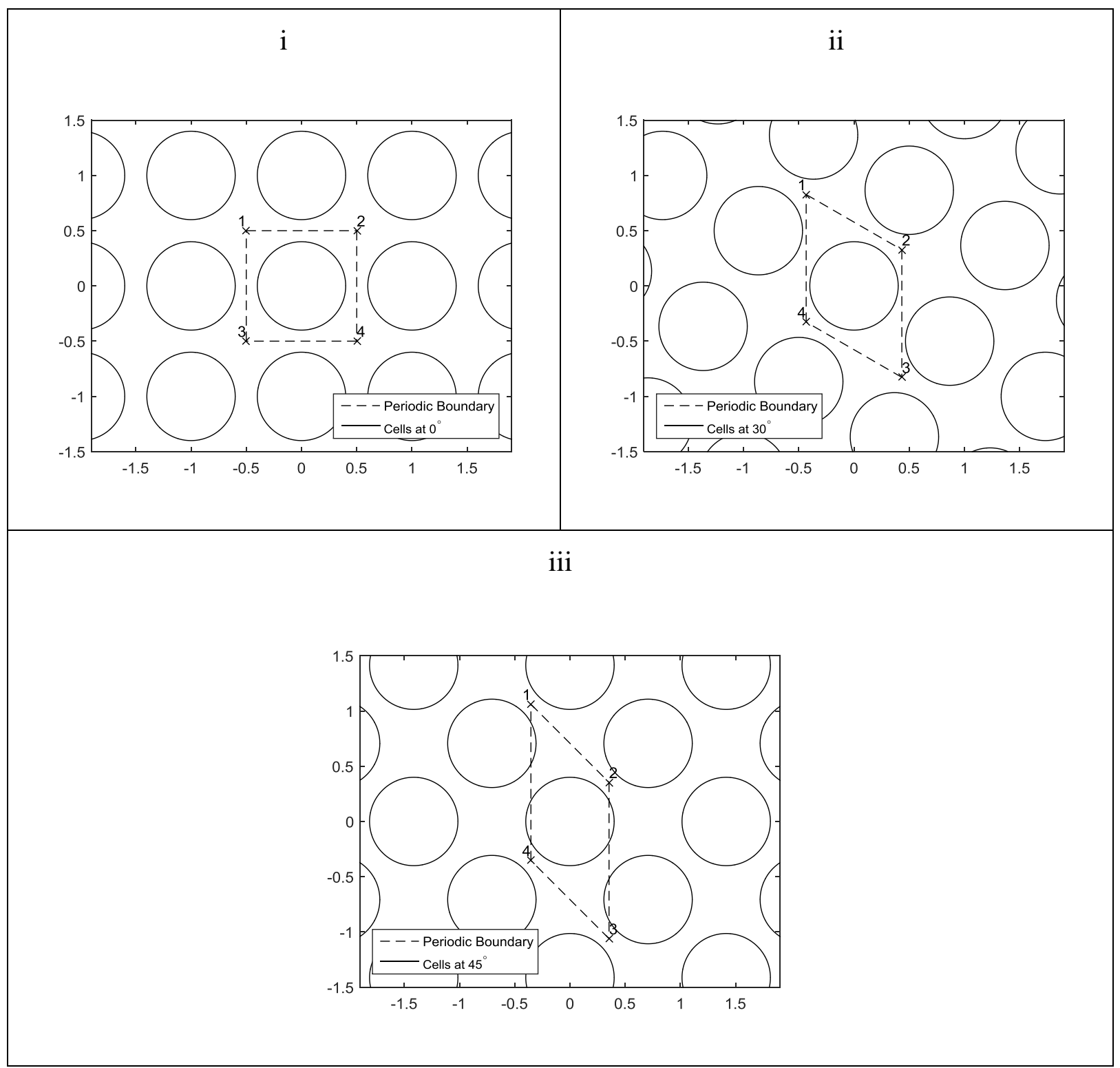

Figure 6: The periodic boundaries are drawn for cell offset angles of $0^{\circ}, 30^{\circ}$ and $45^{\circ}$. The points indicated in each diagram represent points where the pressure and velocity components are constant. The direction of the roll in these diagrams is left to right.

The homogenization of the small scale takes advantage of the cell distribution by locating the domain boundaries periodically. This was done such that the offset from one row of cells to the next can be accounted for by skewing the periodic boundaries as shown in Figure 6 . The net flow field is mapped to its opposing boundary such that $\mathrm{u}_{\mathrm{lhs}}^{*}=\mathrm{u}_{\mathrm{rhs}}^{*}, \mathrm{p}_{\mathrm{lhs}}^{*}=\mathrm{p}_{\mathrm{rhs}}^{*}+\Delta \mathrm{p}^{*}$ and 
$\mathrm{v}_{\mathrm{up}}^{*}=\mathrm{v}_{\mathrm{low}}^{*}, \mathrm{p}_{\mathrm{up}}^{*}=\mathrm{p}_{\text {low }}^{*}$ where $\mathrm{u}^{*}, \mathrm{v}^{*}$ are the velocity components in the roll and axial directions respectively and $\Delta \mathrm{p}^{*}$ is the pressure gradient in the roll direction. The subscripts refer to the left hand (lhs), right hand (rhs), upper (up) and lower (low) boundaries used in Figure 6, and the superscript, *, signifies that the term is only used in the small scale. The points 1-4 in Figure 6 are geometrically the same. Finally, a no-slip boundary is applied to the surface of the roll and the web. 


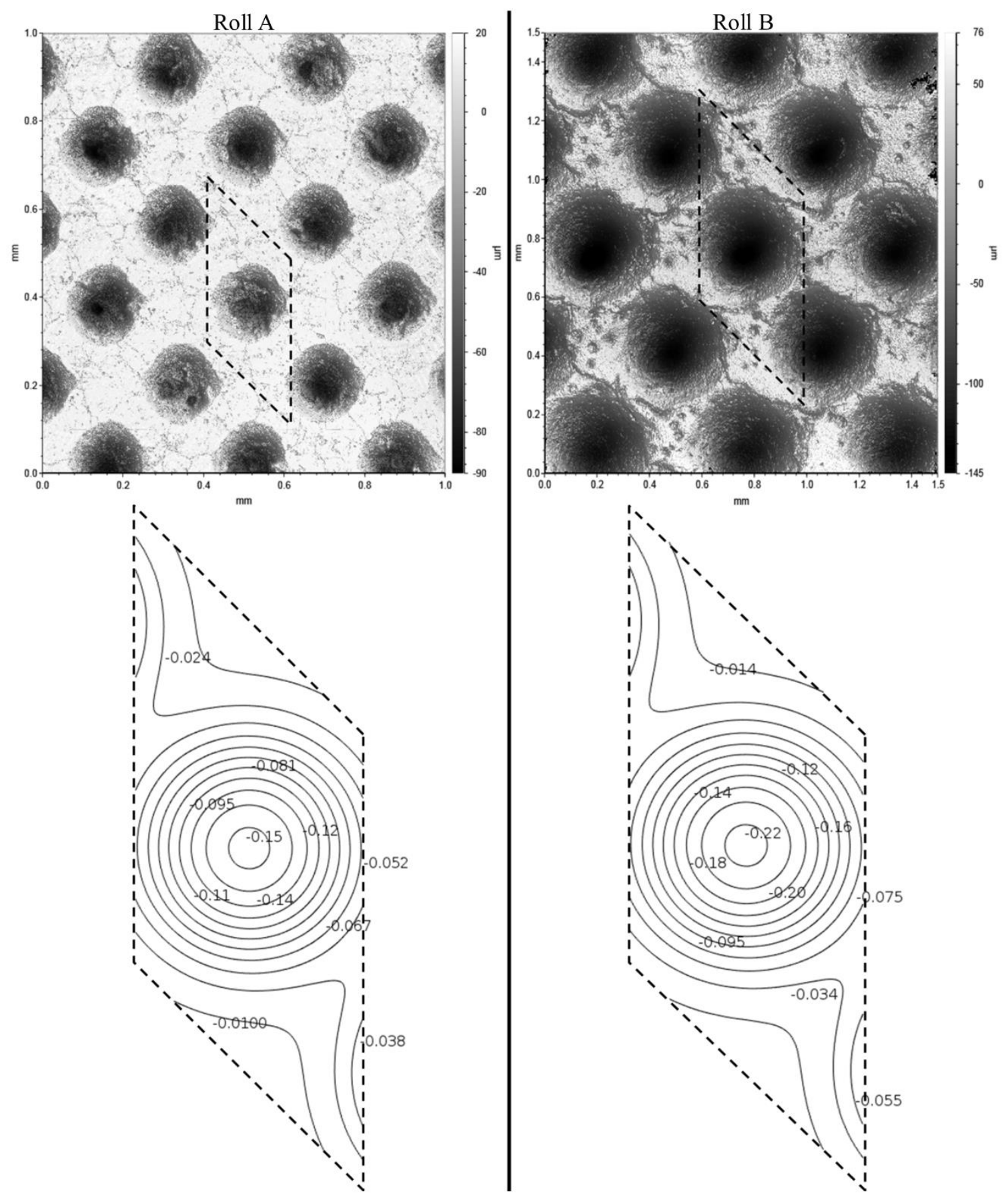

Figure 7: Shown top are the interferometer images of the respective roll surface. The computational representation on the small scale is shown on the bottom. The flow direction on all diagrams is left to right.

The implementation of the small scale surface topography is shown in Figure 7, where interferometer images of each gravure surface are shown. The computational representation 
neglects any non-periodic features, including surface roughness, but the average cell volume was conserved.

\begin{tabular}{|c|c|}
\hline $\mathrm{a}_{\mathrm{L}}=-\frac{\mathrm{g}^{3}}{12}$ & $\mathbf{2 8}$ \\
\hline $\mathrm{b}_{\mathrm{L}}=\frac{\mathrm{g}}{2}$ & $\mathbf{2 9}$ \\
\hline $\mathrm{c}_{\mathrm{L}}=-\frac{\mathrm{g}}{2}$ & 30 \\
\hline
\end{tabular}



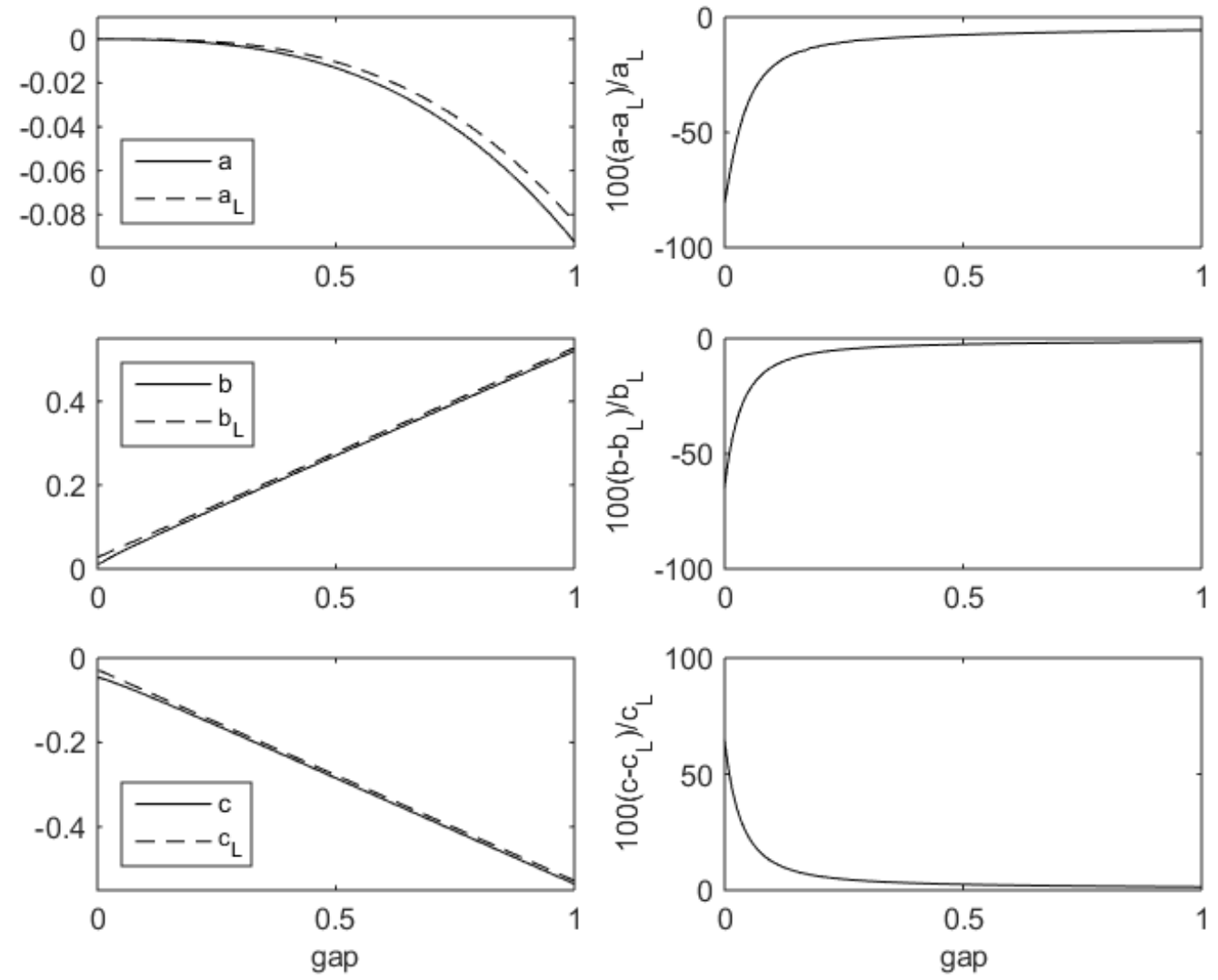

i

ii

Figure 8: Lookup table results for Roll A being compared to an analytic smooth roll solution (i) and the percentage difference (ii). 

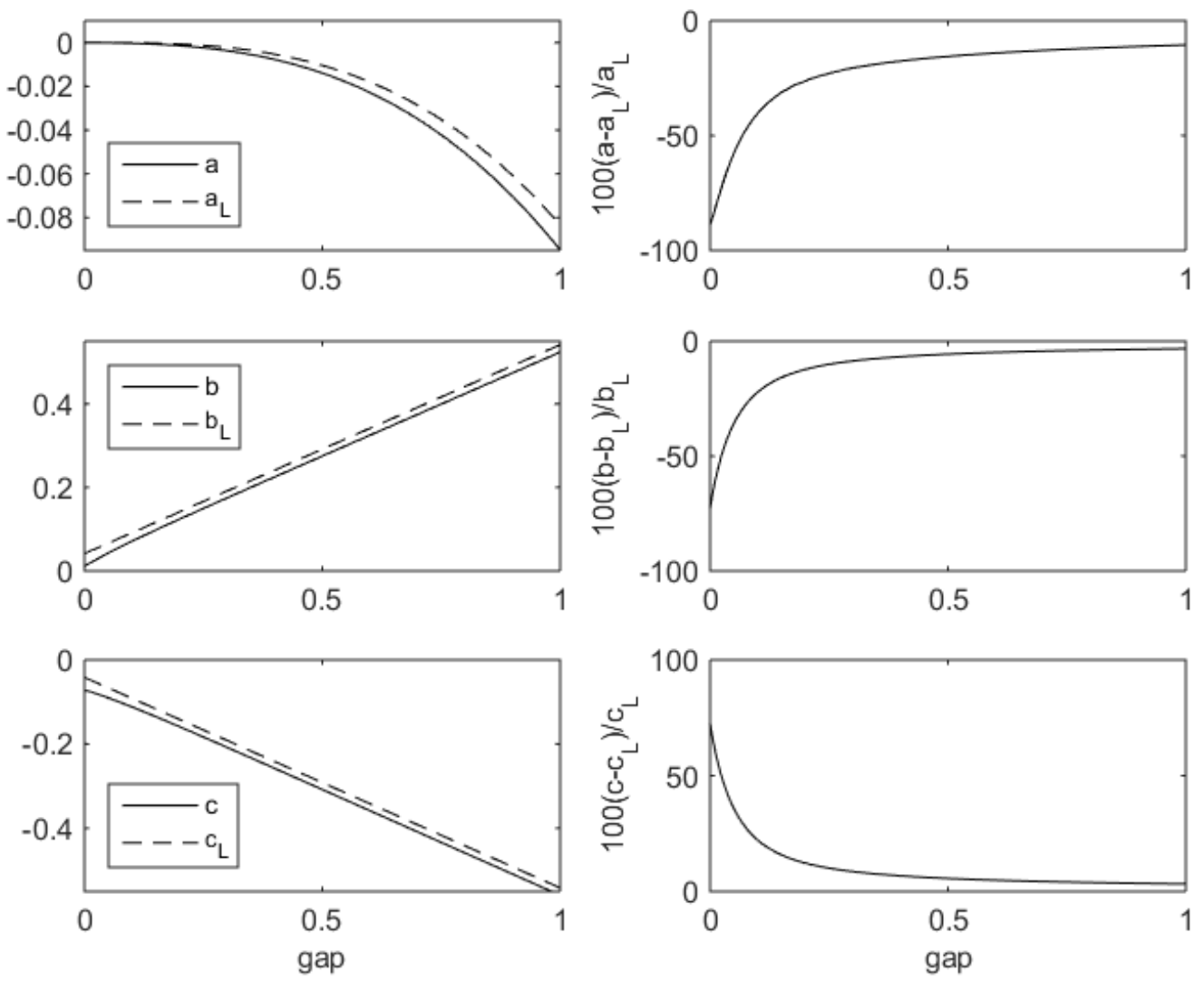

i

ii

Figure 9: Lookup table results for Roll B being compared to an analytic smooth roll solution (i) and the percentage difference (ii).

The data calculated for each lookup table is presented in Figure 8 and Figure 9. These results are presented along with an analytic smooth roll solution derived from lubrication theory (signified throughout by the subscript, L), Equations 28 - 30 (Cameron, 1981). This highlights the additional information captured by accounting for the cell. When the gap is small, the cell represents a substantial portion of the overall volume and therefore in these regions the smooth roll approximation becomes less applicable. 


\subsection{Summary}

The multiscale problem was setup by first creating the small scale data which was stored in a lookup table as a function of the web-to-roll gap. The large scale problem (described by equations 15-20 and boundary conditions 21-27) was solved using MATLAB's bvp4c function. The solution was then iterated on until the error criteria was met (here $\sim 10^{-6}$ ). The gravure operating parameters can be varied in the large scale with the same small scale data set representing the roll. 


\section{Results and Discussion}

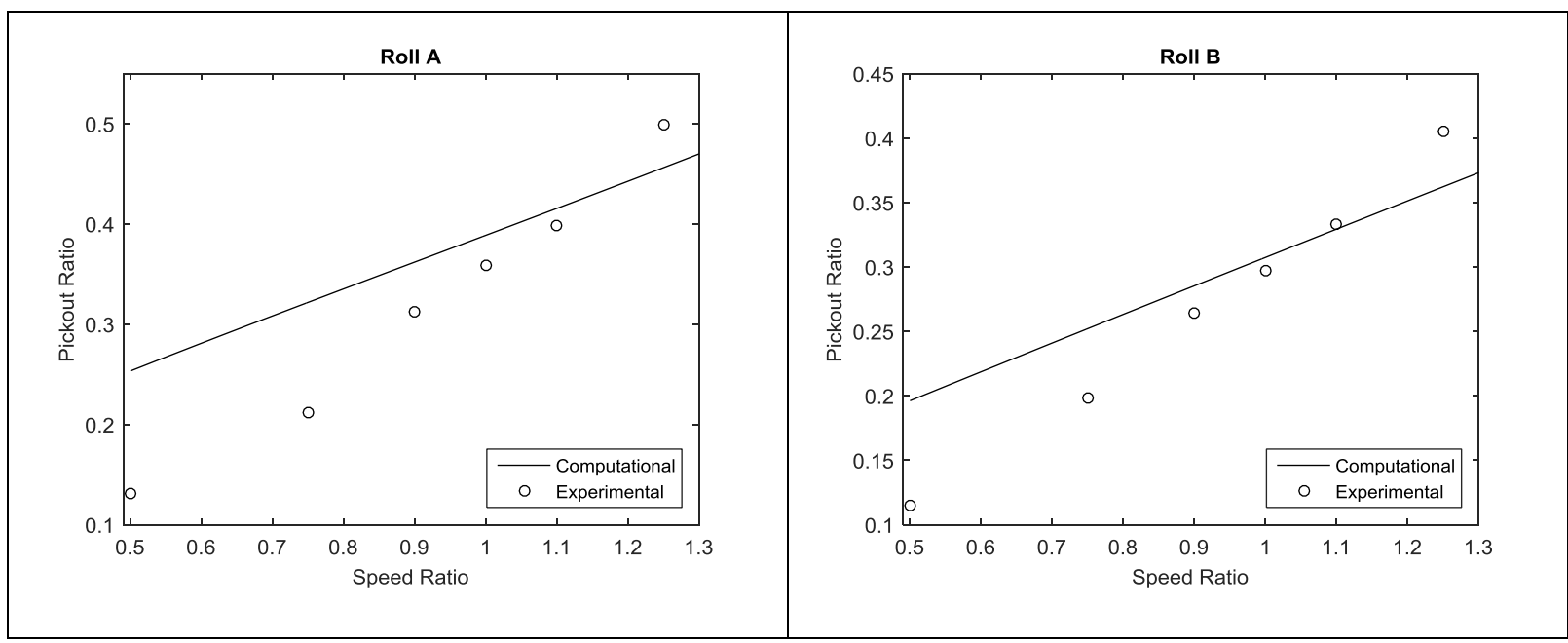

Figure 10: Comparison of computational and experimental results.

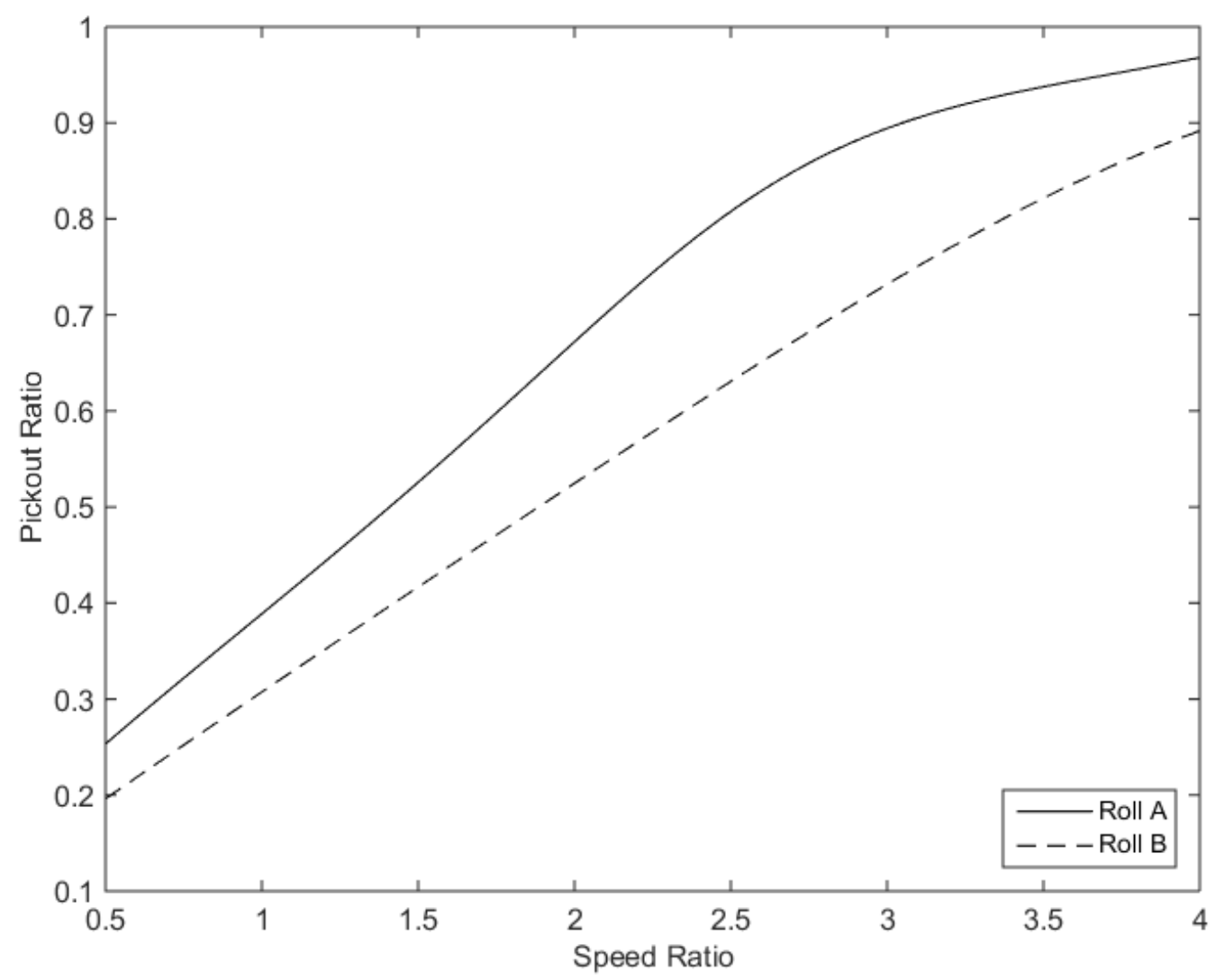

Figure 11: A comparison of the calculated pickout between rolls A and B over an extended range of speed ratios. 
The transfer of fluid from a reverse mode, smooth roll coater to a tensioned flexible web has already been described using lubrication theory [(Gaskell et al., 1998), (Carvalho, 2003)], which indicates that at a speed ratio of one the fluid is completely transferred to the web. This does not reflect the gravure coating scenario, where, at a speed ratio of one the fraction of fluid transfer is approximately one third of the total cell volume. This is shown by the experimental results in Figure 10 and in the previous work of Benkreira and Patel (1993) and Kapur (2003). The results obtained using the HMM, in this paper, captures this effect. The pickout ratio (i.e. the volumetric ratio of fluid transferred to the web from the cell, $\mathrm{q}_{2} / \mathrm{q}_{\text {total }}$ in Figure 3) at a speed ratio of one was calculated to be 0.39 and 0.31 for Rolls A and B respectively. Both are within a few percent of the experimental value. The range of experimental data presented in Figure 10 depicts a linear relation between speed ratio and pickout. This relationship exists when the operating conditions are such that no starvation or flooding occurs at either meniscus and leads to a near constant film thickness. Because of this, gravure coating scales well in industrial operations. The linear trend is also shown using the HMM description. Figure 11 uses numeric data to extend the speed ratio range, approaching a pickout of one where this linear region has clearly ended in Roll A and has begun to bend in Roll B.

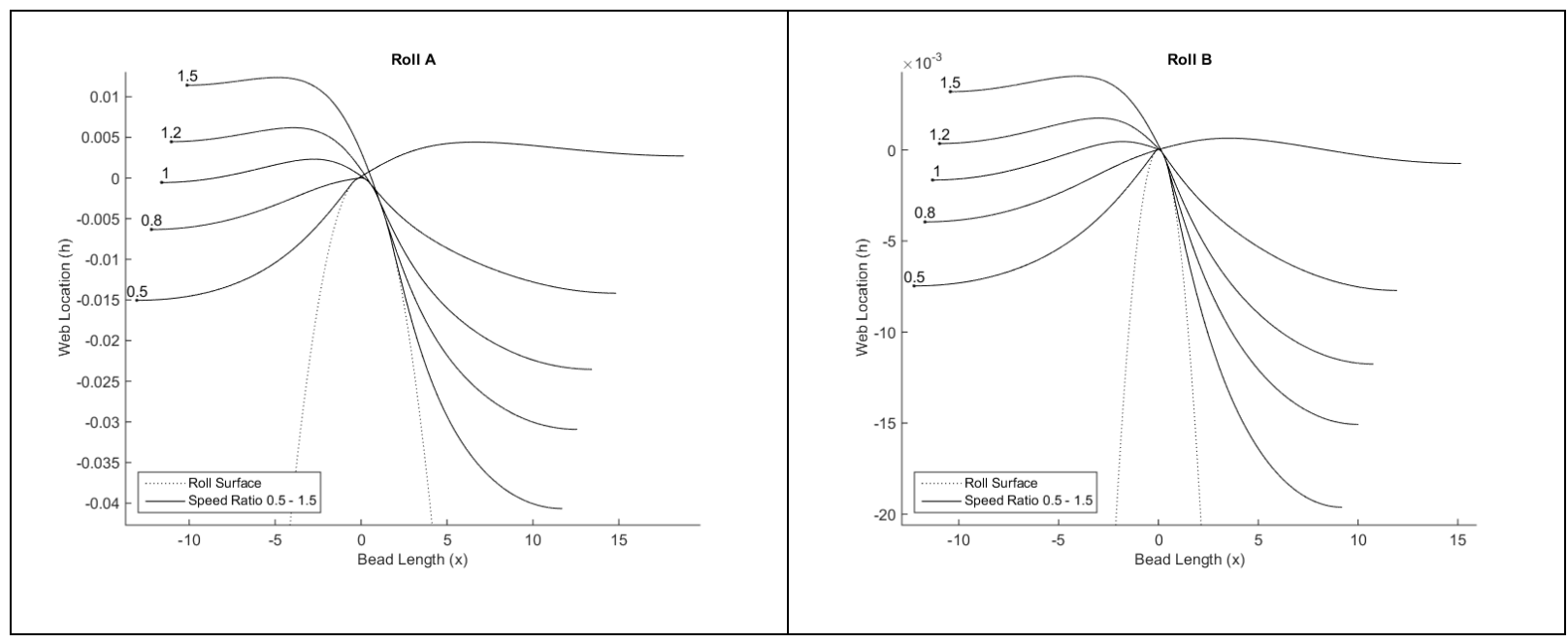

Figure 12: Web position at a range of speed ratios. 
Although this is the first $a b$ initio model to capture the pickout effects there are some differences between it and the experimental results which need further discussion. The small scale model used here assumes a smooth surface in the cell and on the land. In reality the surface is rough, containing pits and sharp fractured edges that form as a result of the laser etching used to manufacture the rolls. This affects the flow field by interrupting the path of fluid near the wall, undermining the no-slip condition by physically displacing the fluid. These effects are not considered in the small scale analysis but become increasing important when the gap is small. The speed ratio changes the shape of the coating bead, and therefore the distribution of small and large gaps (Figure 12). The pressure gradient term has a cubic relation with gap making it particularly sensitive to these changes. Authors investigating lubricating flows in bearings have adopted a stochastic approach to create a homogeneous representation for a flow over a rough surface (Patir and Cheng, 1978), to consider roughness effects which are present at a scale smaller than that of the gravure cell.

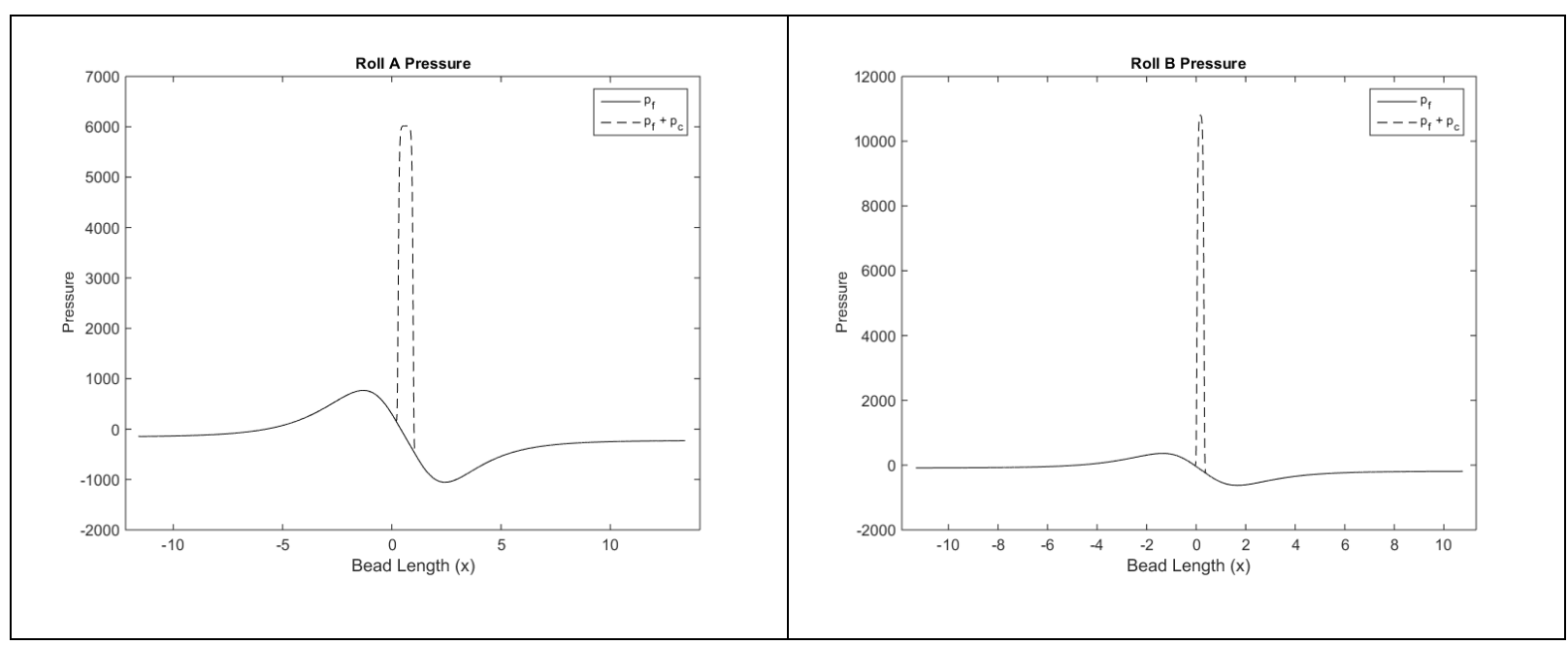

Figure 13: Fluid and contact pressure components across the coating bead. 
There are a number of products that require scratch-free coatings. Currently, to accomplish this at an industrial scale the gravure is placed in an off-set configuration where the fluid is first transferred to an applicator roll with a rubber layer and then to the web. The rubber is elastic and of a similar hardness to the web. It is commercially more efficient to use direct coating, but the direct process cannot be used for scratch-free applications. These scratches occur because the web is briefly in contact with some asperity on the surface of the roll. Figure 13 displays the two pressure components in the coating bead. The fluid component becomes a constant sub-ambient pressure at the menisci while there is a compressionexpansion effect around $\mathrm{x}=0$. The second component is the contact pressure, a measure of the reaction force between the web and roll. Contact occurs in a narrow region immediately down-stream of top-dead-center. The location is influenced by the fluid pressure, which is becoming sub-ambient at $\mathrm{x}=0$, as well as the gap, which increases as the gravure surface curves away from the web as $\mathrm{x} \rightarrow \mathrm{x}_{\mathrm{ds}}$. Therefore, in the contact region there are geometric constraints due to the web being drawn over the apex of the roll and a sub-ambient fluid pressure pulling the web and gravure together. This is the region that leads to web scratches. The elastic layer of an off-set applicator roll prevents this effect by deforming to maintain a thin fluid layer, where the hydrostatic fluid pressure is sufficient to hold the separation. Under typical operating conditions direct gravure roll coating will always be more likely to have some contact component than a smooth roll. This is because fluid can be transported in cells when the web-to-roll gap is zero preventing the high fluid pressures needed to support the web, unlike a smooth roll coater, of any sort, where a gap is either maintained or completely removed as the upstream meniscus collapses into the nip, yielding complete fluid transfer. 


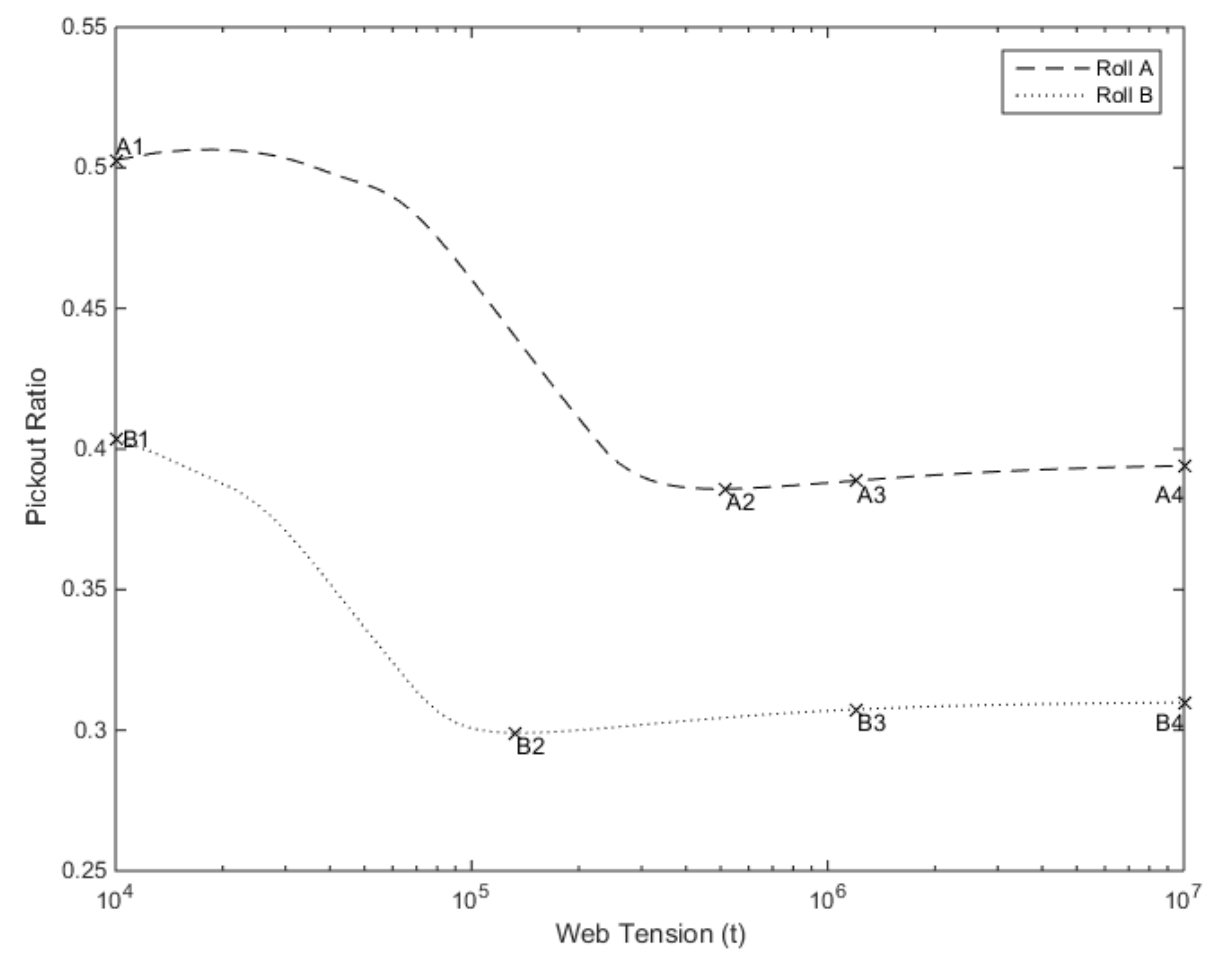

Figure 14: The change in pickout ratio as the non-dimensional web tension is varied. A2 and B2 indicate minimum pickout ratio values. A3 and B3 correspond to the typical industry value 1000 $\mathrm{N} / \mathrm{m}$. 

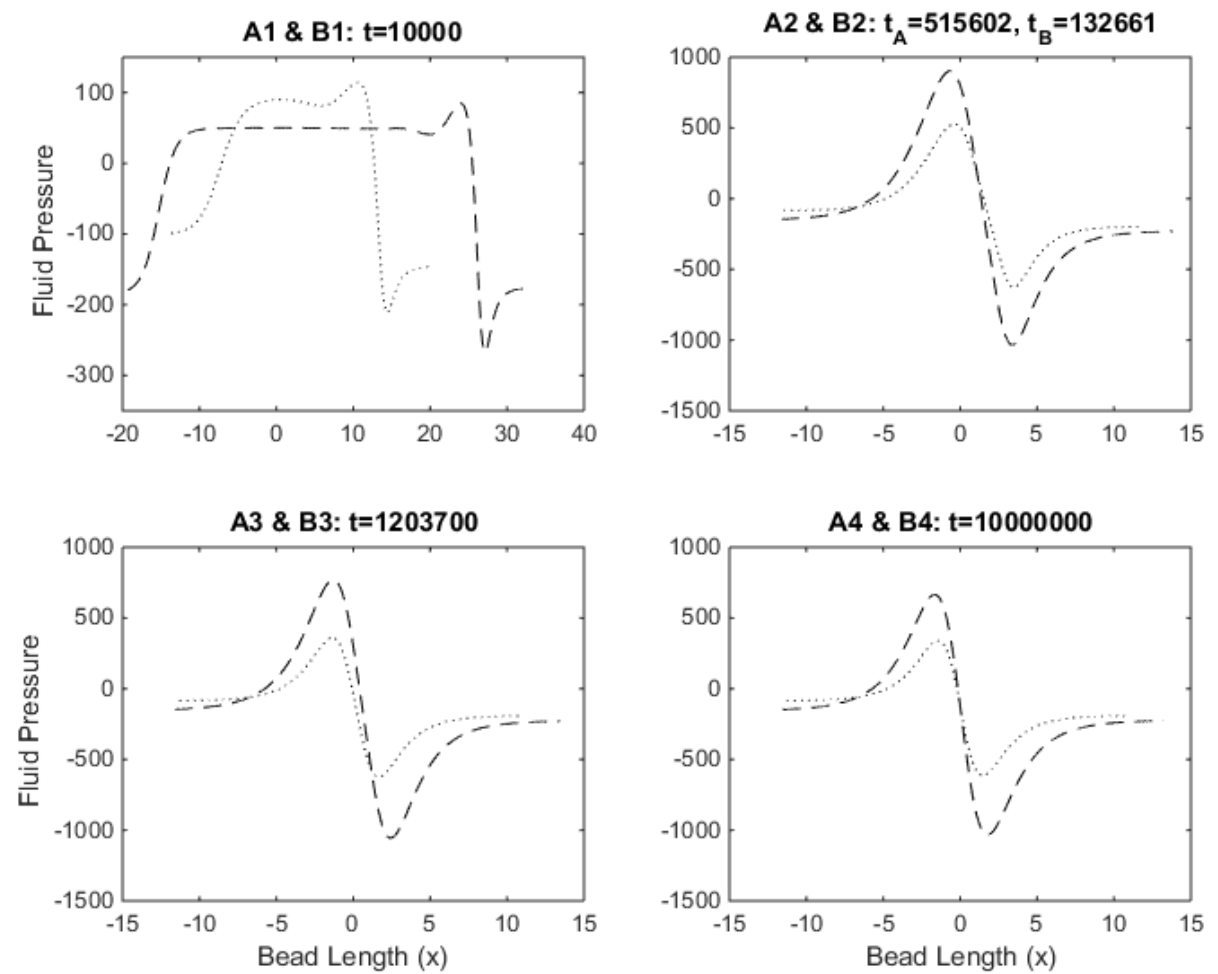

Figure 15: Fluid pressure profiles along the coating bead at the web tensions indicated by the points in Figure 14. Roll A is indicated by the dashed line, Roll B is indicated by the dotted line. 

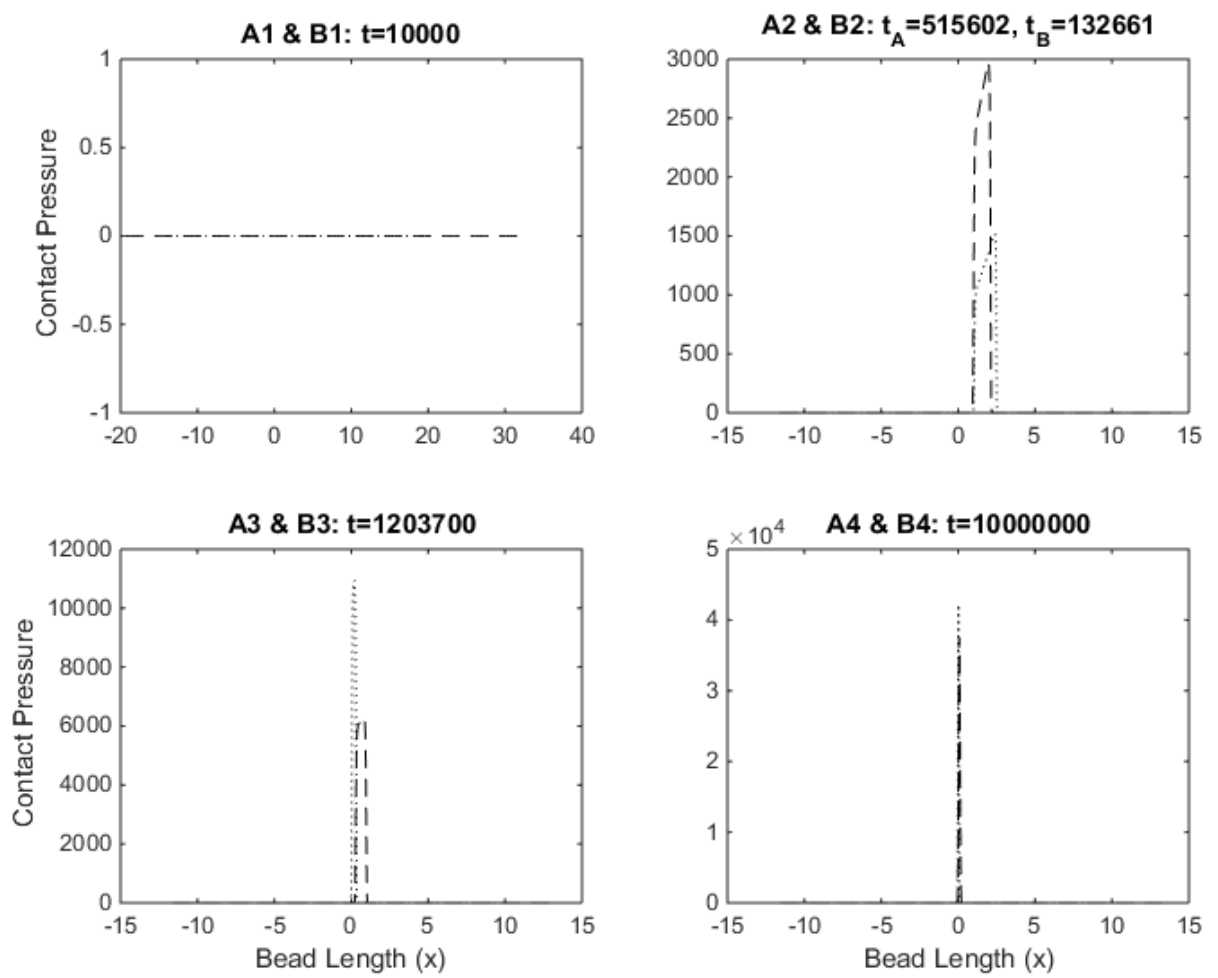

Figure 16: Contact pressure profiles along the coating bead at the web tensions indicated by the points in Figure 14. Roll A is indicated by the dashed line, Roll B is indicated by the dotted line.

The magnitude and length over which the contact pressure acts results from the downward load of the web on the roll. This is related to the web tension and the wrap angle.

First considering the web tension; at typical operating conditions, the pickout ratio is insensitive to web tension. This is because the tension has little effect on the minimum gap, which is being supported by contact with the roll, and therefore minimal effect on the flowrate through the bead, which is instead only dictated by the peripheral velocity of the roll and the volume of the cells. This is indicated by the region of nearly constant pickout in Figure 14, where there is a contact pressure component in the coating bead, Figure 15b-d, while the corresponding effect on hydrostatic pressure is minimal, Figure 16b-d. The minimum gap in this region is zero. At web tensions less than points A2 and B2 in Figure 14 
there is no contact pressure component (Figure 15a) and a positive non-zero minimum gap is maintained throughout the coating bead, creating a region of constant pressure (Figure 14a). This is a similar pressure profile found by Hewson et al (2011) who modelled low tension gravure coating. Pickout ratio is only sensitive to changes in web tension below this point because it leads to changes in minimum gap, thereby adjusting flow rate through the coating bead. It is, however, generally not possible to operate at very low web tensions because it is dictated by other stages in the production line.

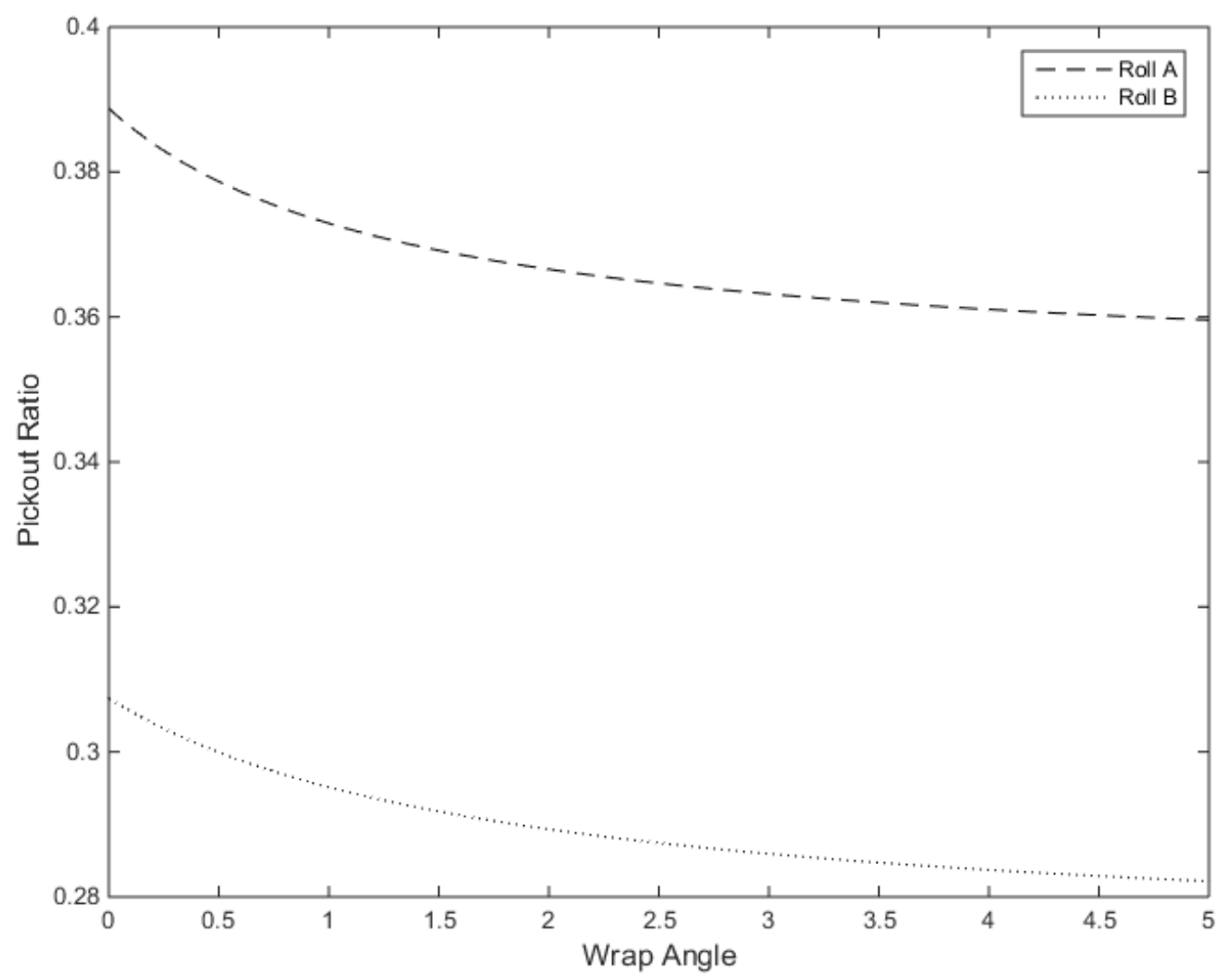

Figure 17: Effect on pickout ratio of parametrically varying the wrap angle. 


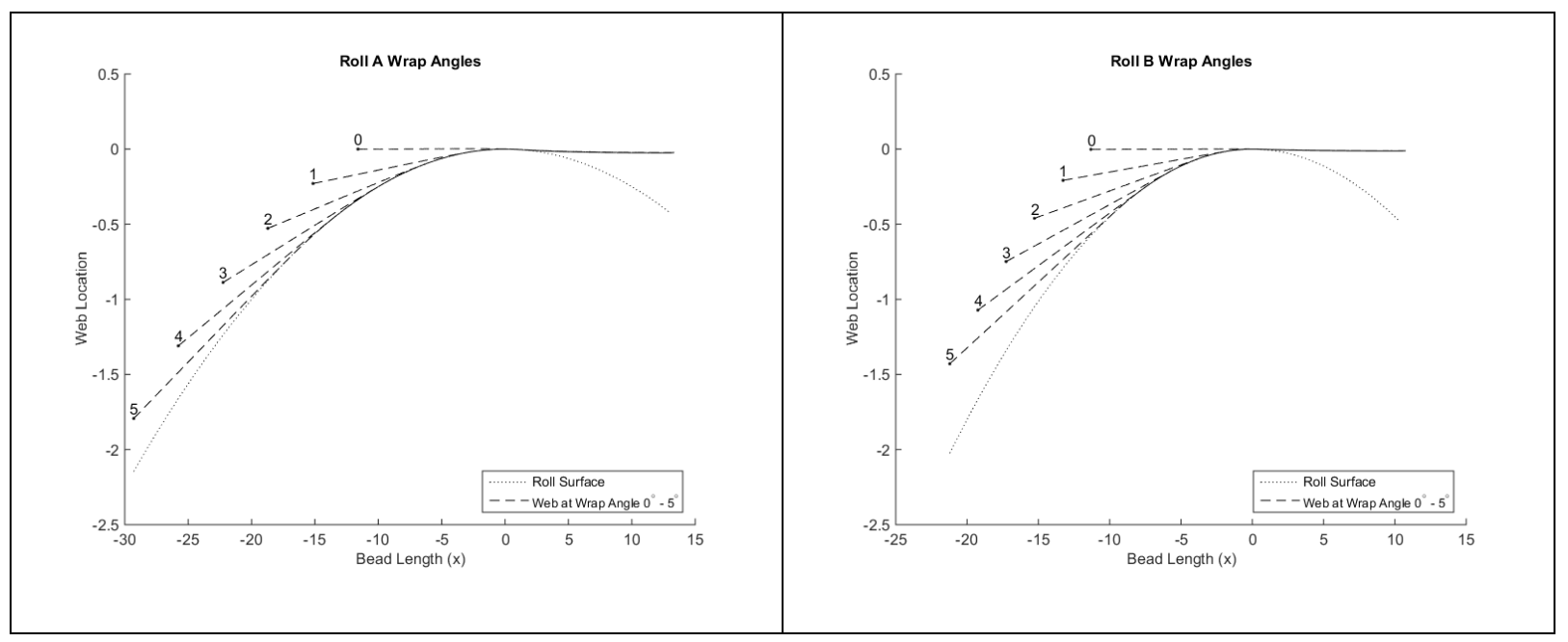

Figure 18: Web location at wrap angles of 0 to 5 degrees.

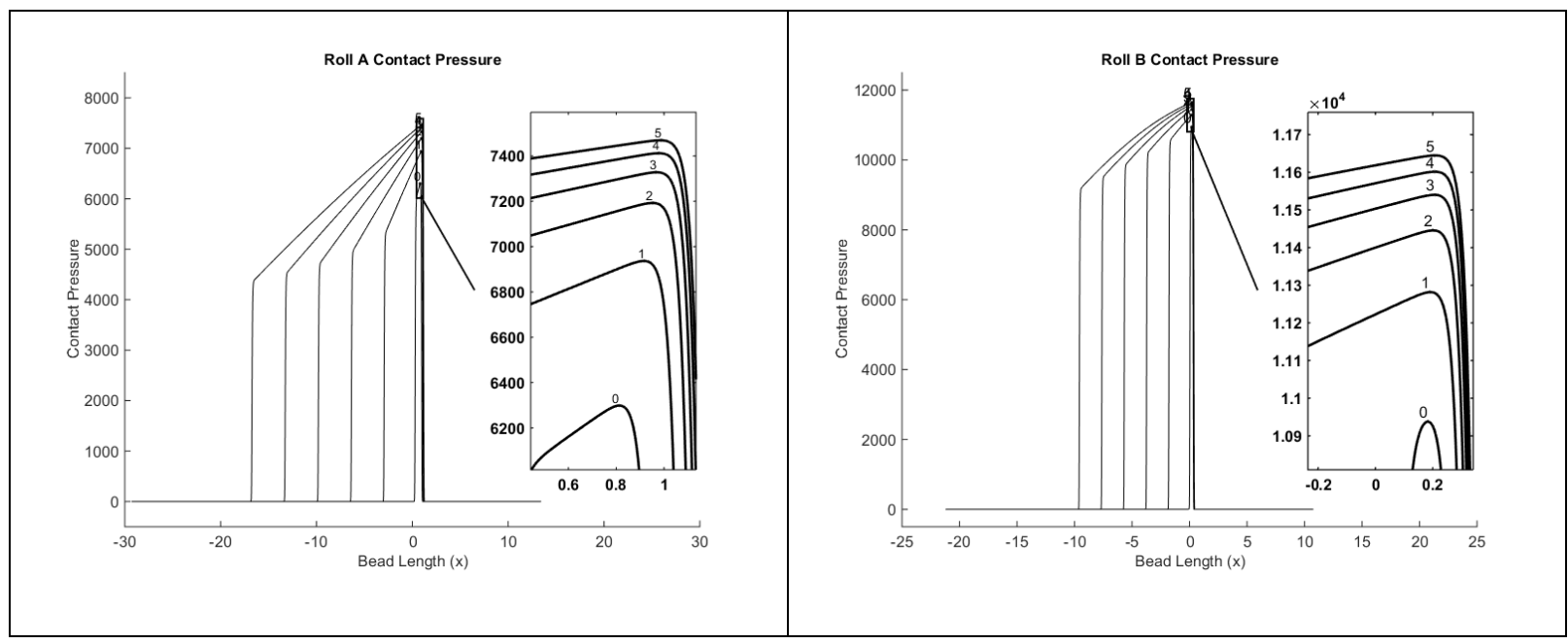

Figure 19: The effect on contact pressure at wrap angles of 0 to 5 degrees.

The wrap angle is set by adjusting the inclination of the incoming web. The angle alters the normal load on the gravure surface subject to $T \sin \theta$ and for typical operating conditions there is a change in pickout ratio of 0.029 and 0.025 for Rolls A and B respectively over a 5 degree change in wrap angle (Figure 17). This is because there is a negligible effect on the minimum gap due to contact, similar to the web tension case described previously. However, the wrap angle does change the shape of the coating bead, which is depicted by plotting the web profile in Figure 18. This serves to increase the length of the contact region as shown in 
Figure 19, suggesting a larger maximum scratch length and an increased scratch probability because of increased exposure to the roll. The total contact load increases as the web is pulled around the roll, creating a larger normal load. The pressure profiles in Figure 19 also show a growth in magnitude along the length of contact. This occurs because the total pressure is a summation of the hydrostatic and contact components and near the roll nip the hydrostatic pressure is transitioning from high to low, leading to a corresponding increase in the contact component.

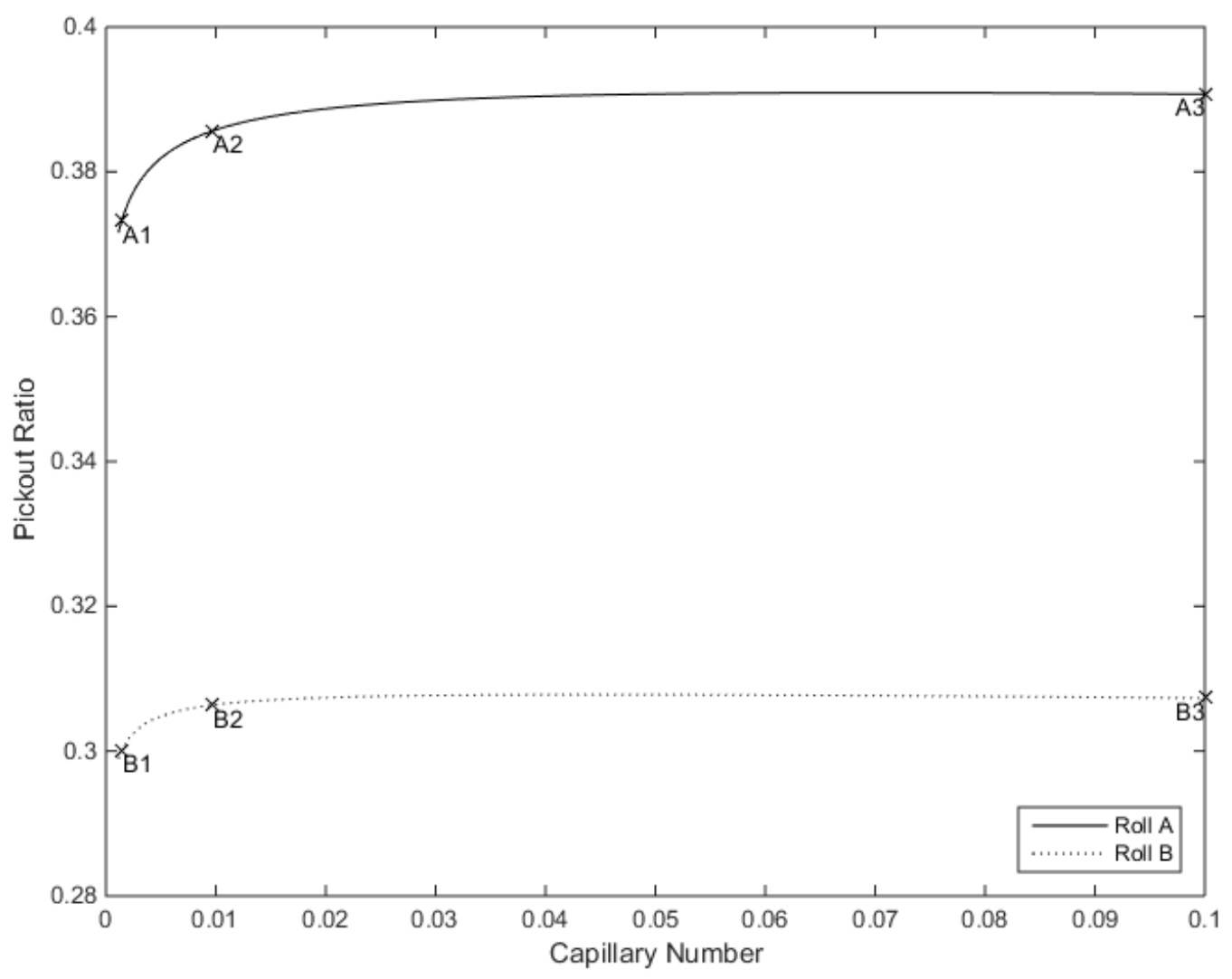

Figure 20: Effect on pickout ratio of parametrically varying the capillary number. 


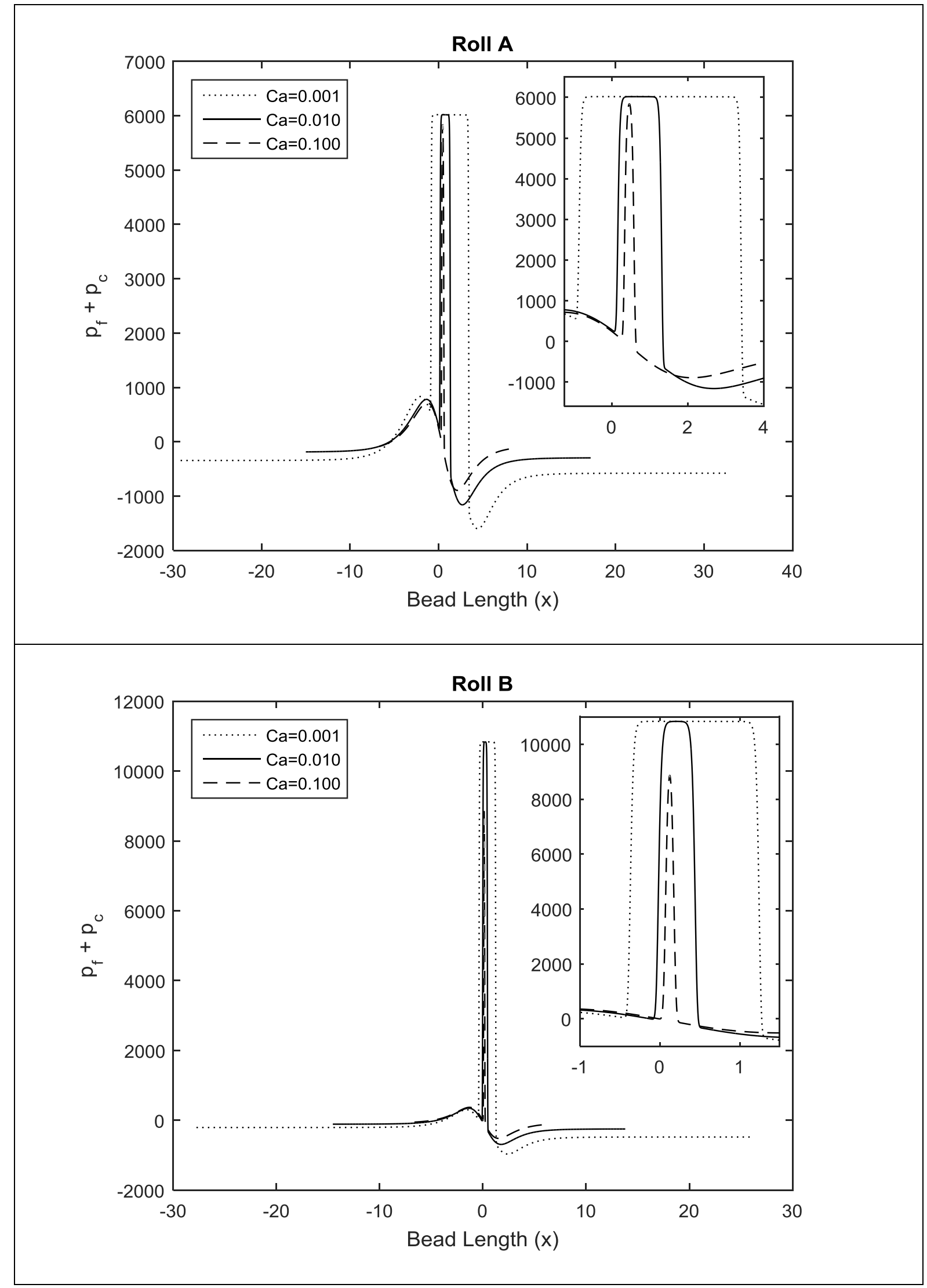

Figure 21: Pressure profiles at the points indicated in Figure 20. The insert in both plots contains a magnified view of the contact region around $x=0$. 
Parametrically varying the capillary number shows an initial increase in pickout ratio that gives way to a region of insensitivity, Figure 20. The trend is visible in the earlier computational work of Hewson and the experimental work of Kapur, however here the magnitude is smaller than Hewson or Kapur. Industrially, the capillary number is altered by changing the concentration of solid particles in the solution, which changes the thickness of the dry coating while maintaining a constant wet coating. Operating in an insensitive capillary region allows the dry coating to be scaled while maintaining production rates. An analysis of the pressures in the coating bead at the points indicated in Figure 20 suggests that there is a reduction in length and contact pressure in the bead (Figure 21). The reduction in bead length corresponds with an increase in surface tension and a decrease in the fluid viscosity.

\section{Conclusion}

This work presents experimental results which have been used as a means of qualitatively validating a two-scale numerical model for the discrete cell gravure coating process. These experimental results agree with those already published [(Benkreira and Patel, 1993) (Kapur, 2003)]. The cell geometries have been presented in detail and were used to inform the numeric model which preserved cell volume, cell patterning and approximated a generic cell shape.

Using a HMM model for the gravure fluid transfer problem allows measurable effects (such as pickout ratio) to be compared with trends that are occurring within the coating bead. Such analysis is experimentally unmanageable due to the size and speed of the cells in operation. Therefore, the work here offers further understanding of how the coating bead behaves in the context of large scale observable trends. 
The model has furthered the work published in (Hewson et al., 2011) where the representation of the small scale has been extended to three-dimensions as well as the inclusion of a contact pressure term in the large scale. This work also moves the web tension into a realistic parameter space. Previously, tension had been underestimated and hence prior to this work no contact model was required. The degree of contact is closely tied to the operating parameters, in particular web tension, where at very low tensions a no contact region exists. The inclusion of contact poses an interesting direction for further study of scratches formed on the web due to contact with the roll.

\section{Acknowledgements}

The authors would like to acknowledge Raske's studentship funding provided by the UK EPSRC (voucher number 08002966) and DuPont Teijin Films. The data underpinning this paper is openly available at http://doi.org/10.5518/56.

\section{References}

BECERRA, M. \& CARVALHO, M., S. 2011. Stability of viscoelastic liquid curtain. Chemical Engineering and Processing, 50, 445-449.

BENKREIRA, H., EDWARDS, M. F. \& WILKINSON, W. L. 1982. Mathematical modelling of the reverse and metering roll coating flow of newtonian fluids. Chemical Engineering Sciences, 277-282.

BENKREIRA, H. \& PATEL, R. 1993. Direct gravure roll coating. Chemical engineering science, 48, 2329-2335.

BOOTH, G. L. 1970. Coating equipment and processes. New York: Lockwood Publishing Company.

BRETHERTON, F. 1961. The motion of long bubbles in tubes. Journal of Fluid Mechanics, $10,166-188$.

CAMERON, A. 1981. Basic Lubrication Theory, Chichester, Ellis Horwood Limited. 
CARVALHO, M. \& SCRIVEN, L. 1997. Flows in forward deformable roll coating gaps: comparison between spring and plane-strain models of roll cover. Journal of Computational Physics, 138, 449-479.

CARVALHO, M. D. S. 2003. Elastohydrodynamics of tensioned web roll coating process. International journal for numerical methods in Fluids, 41, 561-576.

COYLE, D., MACOSKO, C. \& SCRIVEN, L. 1990. The fluid dynamics of reverse roll coating. AIChE Journal, 36, 161-174.

DE BOER, G., GAO, L., HEWSON, R. \& THOMPSON, H. 2016. Heterogeneous Multiscale Methods for modelling surface topography in EHL line contacts. Tribology International.

DE BOER, G., N., HEWSON, R., W., THOMPSON, H., M., GAO, L. \& TOROPOV, V., V. 2014. Two-scale EHL: Three-dimensional topography in tilted-pad bearings. Tibology International, 111-125.

DE KRAKER, A., VAN OSTAYEN, R., A.J. \& RIXEN, D., J. 2010. Development of a texture averaged Reynolds equation. Tribology Internaltional, 43, 2100-2109.

DE KRAKER, A., VAN OSTAYEN, R. A., VAN BEEK, A. \& RIXEN, D. J. 2007. A multiscale method modeling surface texture effects. Journal of tribology, 129, 221230.

DODDS, S., CARVALHO, M. \& KUMAR, S. 2011. Stretching liquid bridges with moving contact lines: The role of inertia. Physics of Fluids, 23.

DODDS, S., CARVALHO, M. D. \& KUMAR, S. 2009. Stretching and slipping of liquid bridges near plates and cavities. Physics of Fluids, 21.

GAO, L., DE BOER, G., N. \& HEWSON, R. W. 2015. The role of micro-cavitation on EHL: A multiscale mass conserving approach. Tribology International, 324-331.

GAO, L. \& HEWSON, R. 2012. A multiscale framework for EHL and micro-EHL. Tribology Transactions, 55, 713-722.

GAO, L., HEWSON, R., THOMPSON, H., RASKE, N. \& TOROPOV, V. 2016. A multiscale method for optimising surface topography in elastohydrodynamic lubrication (EHL) using metamodels.

GASKELL, P. H., REES, S. R., SAVAGE, M. D. \& STOREY, S. P. 1998. A mathematical model of roll-to-web kiss coating. Trans IChemE, Vol 76, Part A, 29-37.

GREENER, J. \& MIDDLEMAN, S. 1979. Theoretical and experimental studies of the fluid dynamics of a two-roll coater. Ind. Eng. chem. Fund., 35-41.

HANUMANTHU, R. 1999. Variation of gravure coating thickness during early stages of doctor blade wear. AIChE, 45, 2487-2494.

HEWSON, R., KAPUR, N. \& GASKELL, P. 2011. A two-scale model for discrete cell gravure roll coating. Chemical Engineering Science, 66, 3666-3674.

HEWSON, R., W., KAPUR, N. \& GASKELL, P., H. 2006. A theoretical and experimental investigation of tri-helical gravure roll coating. Chemical Engineering Science, 54875499.

HODA, N. \& KUMAR, S. 2008. Boundary integral simulations of liquid emptying from a model gravure cell. Physics of Fluids 20,092106. 
HUANG, W.-X., LEE, S.-H., SUNG, H., JIN, LEE, T.-M. \& KIM, D.-S. 2008. Simulation of liquid transfer between separating walls for modeling micro-gravure-offset printing. International Journal of Heat and Fluid Flow, 29, 1436-1446.

JALKANEN, T., MÄKILÄ, E., MÄÄTTÄNEN, A., TUURA, J., KAASALAINEN, M., LEHTO, V.-P., IHALAINEN, P., PELTONEN, J. \& SALONEN, J. 2012. Porous silicon micro- and nanoparticles for printed humidity sensors. Applied Physics Letters, $101,1-4$.

JIN, J., KO, J.-H., YANG, S. \& BAE, B.-S. 2010. Rollable transparent glass-fabric reinforced composite substrate for flexible devices. Advanced Materials, 22, 4510-4515.

KAPUR, N. 1999. Flow phenomena in fixed-gap and gravure roll coating sytems, PHD Thesis, University of Leeds.

KAPUR, N. 2003. A parametric study of direct gravure coating. Chemical Engineering Science 58, 2875-2882.

KAPUR, N., GASKELL, P. H. \& BATES, A. 2001. A parametric study of offset gravure coating. Chemical Engineering Research \& Design, 79, 41-50.

KREBS, F. C. 2009. Fabrication and processing of polymer solar cells: a review of printing and coating techniques. Solar Energy Materials and Solar Cells, 93, 394-412.

KUMAR, S. 2015. Liquid Transfer in Printing Processes: Liquid Bridges with Moving Contact Lines. Annual Review of Fluid Mechanics, Vol 47, 47, 67-94.

LANDAU, L. 1942. B., Levich,“. Dragging of a Liquid by a Moving Plate,” Acta Physicochim. URSS, 17, 42.

MÄKELÄ, T., HAATAINEN, T., MAJANDER, P. \& AHOPELTO, J. 2007. Continuous roll to roll nanoimprinting of inherently conducting polyaniline. Microelectronic Engineering, 84, 877-879.

MICHELS, J., J., PETER, M., SALEM, A., VAN REMOORTERE, B. \& VAN DEN BRAND, J. 2014. A combined experimental and theoretical study on the side ingress of water into barrier adhesives for organic electronics applications. Journal of Materials Chemistry C, 2, 5759-5768.

PATIR, N. \& CHENG, H. S. 1978. An Average Flow Model for Determining Effects of Three-Dimensional Roughness on Partial Hydrodynamic Lubrication. Journal of Lubrication Technology, 100, 12-17.

PÉREZ-RÀFOLS, F., LARSSON, R., LUNDSTRÖM, S., WALL, P. \& ALMQVIST, A. A stochastic two-scale model for pressure-driven flow between rough surfaces. Proc. R. Soc. A, 2016. The Royal Society, 20160069.

POOLE, J., L. 1981. Fluid metering roller. United States of America patent application.

POWELL, C. A., SAVAGE, M. D. \& GASKELL, P. H. 2000. Modelling the meniscus evacuation problem in direct gravure coating. IChemE, Vol 78, Part A, 61-67.

PUDAS, M., , H., NIINA, GRANAT, P. \& VÄHÄKANGAS, J. 2005. Gravure printing of conductive particulate polymer inks on flexible subtrates. Progress in Organic Coatings, 54, 310-316.

PUDAS, M., HAGBERG, J. \& LEPPÄVUORI, S. 2004. Gravure offset printing of polymer inks for conductors. Progress in Organic Coatings, 49, 324-335. 
REES, S. R. 1995. An experimental and theoretical investigation of gravure roll coating, University of Leeds; PhD Thesis.

ROMERO, O., J., SCRIVEN, L., E. \& CARVALHO, M., S. 2006. Slot coating of mildly viscoelastic liquids. J. Non-Newtonian Fluid Mech., 138, 63-75.

SAHLIN, F., ALMQVIST, A., LARSSON, R. \& GLAVATSKIH, S. 2007. A cavitation algorithm for arbitrary lubricant compressibility. Tribology International, 40, 12941300.

SCHWARTZ, L., MOUSSALlI, P., CAMPBELL, P. \& ELEY, R. 1998. Numerical Modelling of Liquid Withdrawal from Gravure Cavities in Coating Operations. IChemE, Vol 76.

STOREY, S., P. 1996. A theoretical investigation of the flow between a web and roll, with application to gravure coating. PhD Thesis, University of Leeds.

TOBJÖRK, D., KAIHOVIRTA, N., J, MÄKELÄ, T., PETTERSSON, F., S \& ÖSTERBACKA, R. 2008. All-printed low-voltage organic transistors. Organic Electronics, 9, 931-935.

YIN, X. \& KUMAR, S. 2005. Lubrication flow between a cavity and a flexible wall. Physics of Fluids.

YIN, X. \& KUMAR, S. 2006. Two-dimensional simulations of flow near a cavity and a flexible solid boundary. Physics of Fluids 18,063103. 